DOE/NV/25946--1554

\title{
FEDERAL RADIOLOGICAL MONITORING AND ASSESSMENT CENTER \\ Monitoring Manual Volume 1 \\ Operations
}

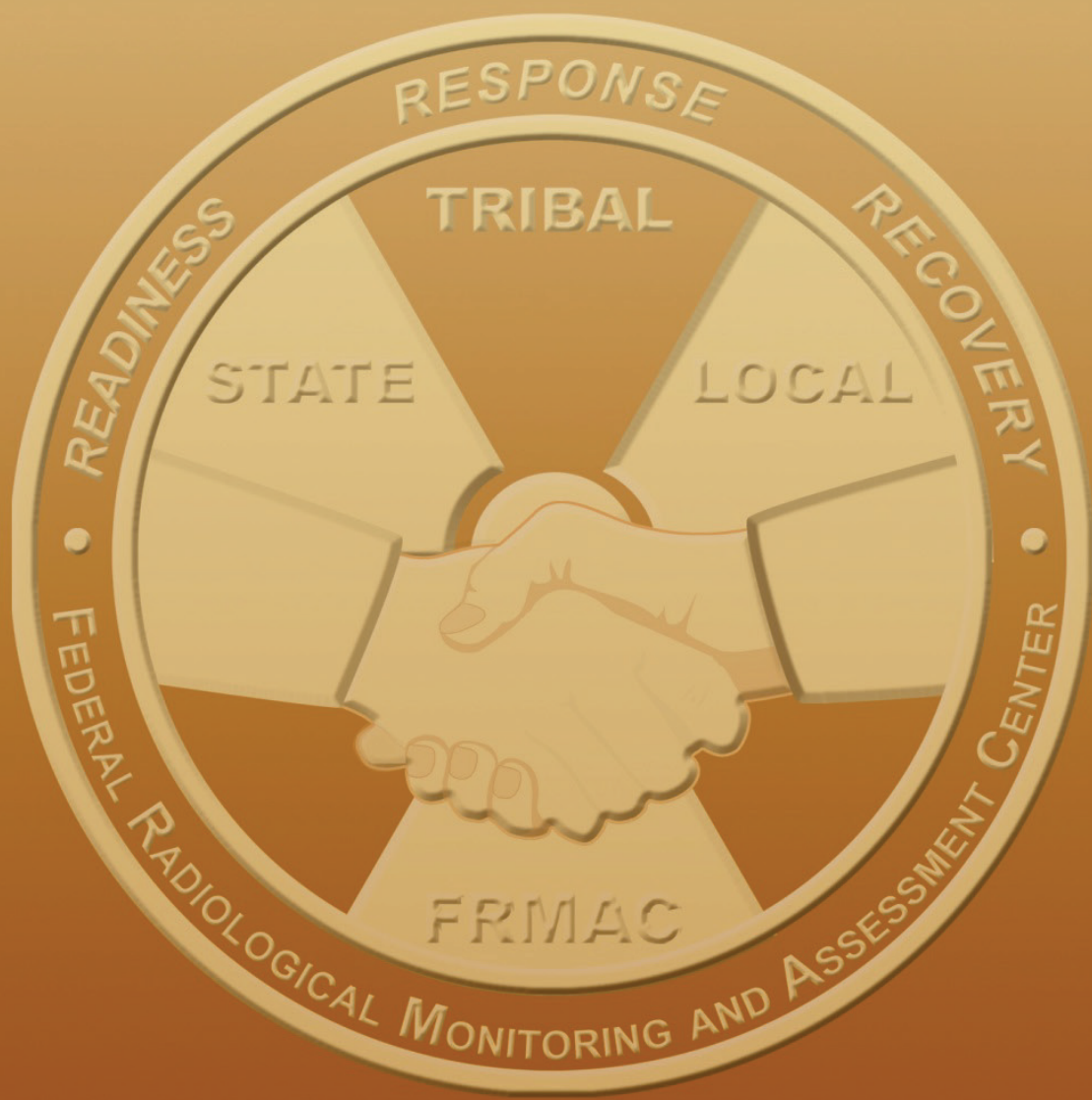

July 2012 


\section{DISCLAIMER}

This report was prepared as an account of work sponsored by an agency of the U.S. Government. Neither the U.S. Government nor any agency thereof, nor any of their employees, nor any of their contractors, subcontractors or their employees, makes any warranty or representation, express or implied, or assumes any legal liability or responsibility for the accuracy, completeness, or usefulness of any information, apparatus, product, or process disclosed, or represents that its use would not infringe privately owned rights. Reference herein to any specific commercial product, process, or service by trade name, trademark, manufacturer, or otherwise, does not necessarily constitute or imply its endorsement, recommendation, or favoring by the U.S. Government or any agency thereof. The views and opinions of authors expressed herein do not necessarily state or reflect those of the U.S. Government or any agency thereof. 


\section{FEDERAL RADIOLOGICAL MONITORING AND ASSESSMENT CENTER Monitoring Manual}

Volume 1

\section{Operations}

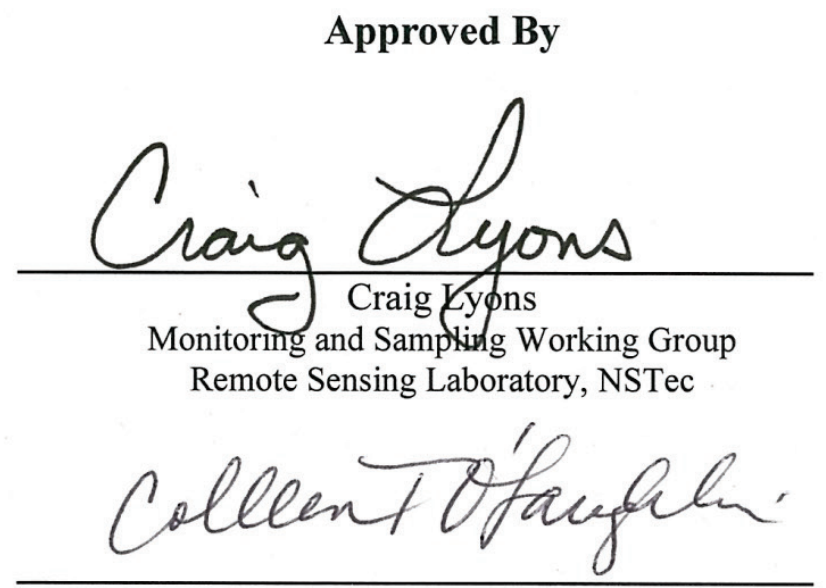

Colleen T. O'Laughlin, Program Manager

Consequence Management/Federal Radiological Monitoring and Assessment Center

U.S. Department of Energy, National Nuclear Security Administration

Nevada Site Office, Las Vegas, NV

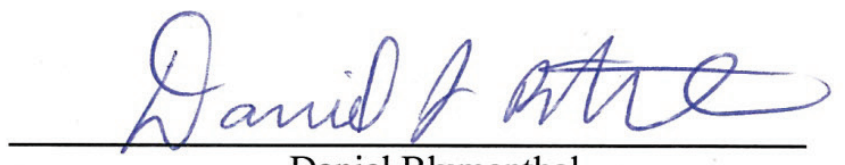

Daniel Blumenthal

Consequence Management Program Manager

Office of Emergency Response

U.S. Department of Energy, National Nuclear Security Administration

Headquarters Office of Emergency Operations

Washington, D.C.

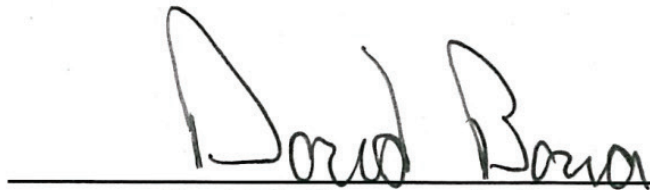

David R. Bowman, Acting Director

Office of Emergency Response

U.S. Department of Energy, National Nuclear Security Administration

Headquarters Office of Emergency Operations

Washington, D.C.

This Document is UNCLASSIFIED

Angela Anderson

Derivative Classifier 
This page intentionally left blank 
FRMAC MONITORING DIVISION MANUAL VOL. 1

\section{REVISION HISTORY}

\begin{tabular}{lll} 
Date & Pages Changed & Revision \\
\hline September 2002 & Original & Rev. 0 \\
December 2005 & Realignment with NRP & Rev. 1 \\
July 2012 & Complete revision & Rev. 2
\end{tabular}


This page intentionally left blank 


\section{ACKNOWLEDGEMENTS}

The FRMAC Monitoring Working Group and several additional individuals contributed their time and efforts in writing and/or reviewing this document. These individuals are recognized below.

\section{FRMAC Monitoring Working Group}

Chair, Craig Lyons National Security Technologies, LLC

Robert Augdahl National Security Technologies, LLC

Michael Ferriola U.S. Environmental Protection Agency

Roger Goodman U.S. Environmental Protection Agency

Paul Greenbaum National Security Technologies, LLC

Michael Howe U.S. Department of Homeland Security / FEMA

Terry Kraus Sandia National Laboratory

C. E. Maples Y-12 National Security Complex

Toby Morales State of Arizona

Colleen O'Laughlin U.S. Department of Energy

Joshua Pate U.S. Environmental Protection Agency

Peter A. Petch U.S. Environmental Protection Agency Sam Poppell U.S. Environmental Protection Agency

Mark Sells U.S. Environmental Protection Agency

Arthur Shanks Sandia National Laboratory

Rich Sorom National Security Technologies, LLC

Chuck Strain Savannah River Site / RAP Region 3

Bob Stueckrath National Security Technologies, LLC

Richard Stump Sandia National Laboratory / RAP Region 4

Dan Sweeney U.S. Department of Defense

Lori Thomas U.S. Department of Energy

Don Van Etten National Security Technologies, LLC

Steve Woods California Department of Homeland Security

\section{Additional Contributors}

Charles Adams Florida Bureau of Radiation Control

Allan Allshouse National Security Technology, LLC

Brennen Brunner MN Homeland Security and Emergency Management 
This page intentionally left blank 


\section{CONTENTS}

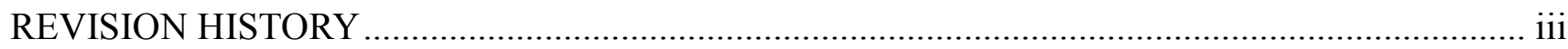

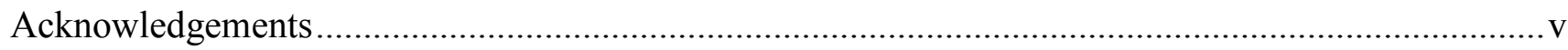

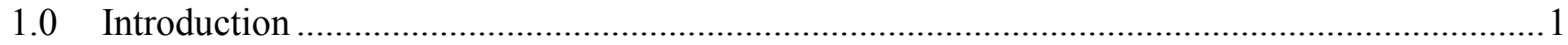

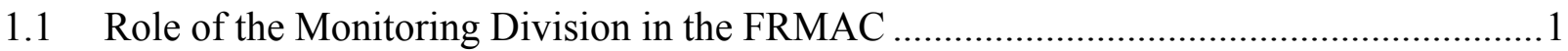

1.2 Duties of the Monitoring Division Manager …………................................................

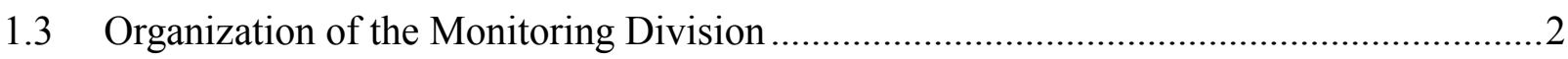

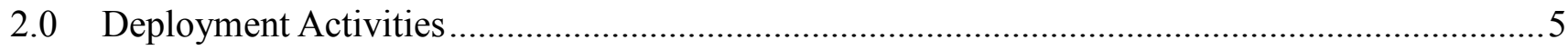

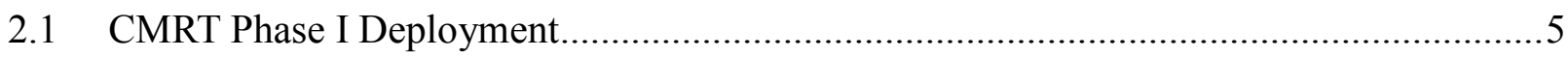

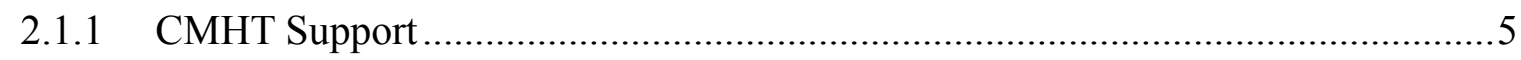

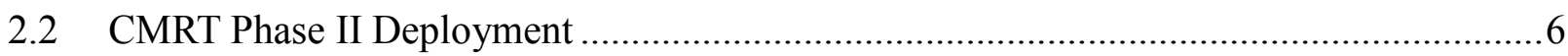

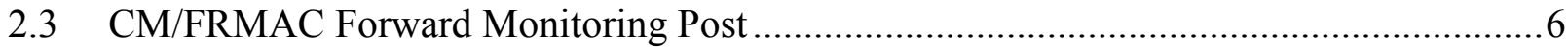

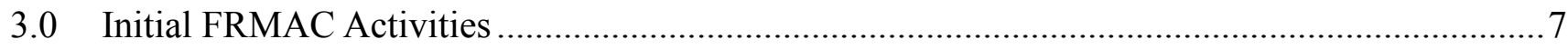

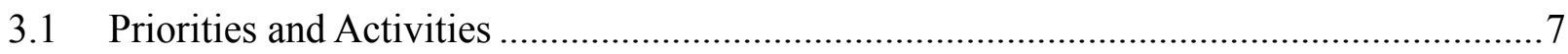

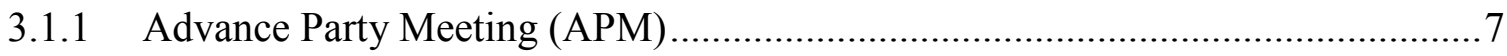

3.1.2 Interaction with State, Local, Tribal, or Other Federal Agencies ............................9

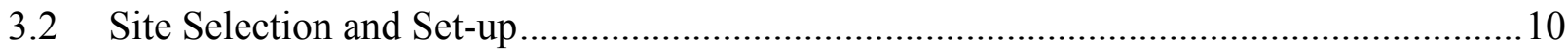

3.3 CMRT Phase I Initial Monitoring Team Deployment ...................................................... 12

3.3.1 Ten Point Monitoring Strategy …………………….........................................13

4.0 Developing and Implementing the Monitoring and Assessment Plan ........................................ 15

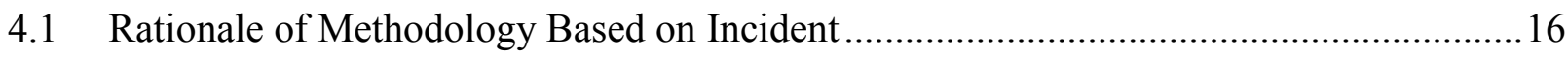

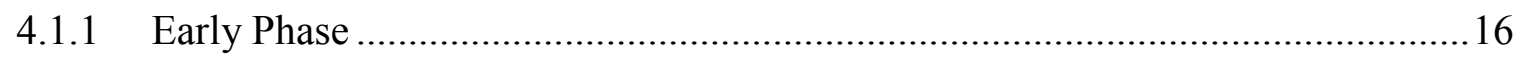

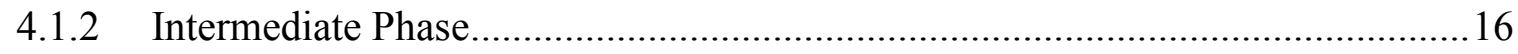

4.1.3 Ability to Detect Key Radionuclides Using Field Instruments ..............................16

4.1.4 Ability to Detect Continuous Plume or Waterborne Releases................................17

4.1.5 Deposition Measurement by Ground Teams ………............................................ 17

4.1.6 Deposition Measurements by Aircraft.............................................................. 18

4.1.7 Monitoring of Shelter-In-Place Locations …………......................................21

4.1.8 Monitoring of Critical Institutions, Facilities, Transportation Corridors and Residences Where People Must Reenter in the Near Future. 


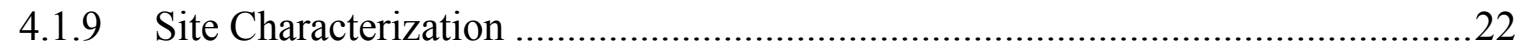

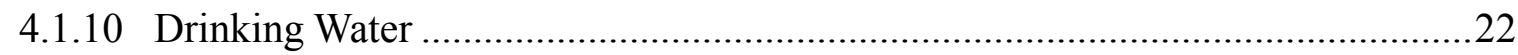

4.1.11 Farms, Dairies, and Food Processing Plants ..............................................23

4.2 Develop Daily Implementation Plan ...................................................................23

4.3 Specific Monitoring and Sampling Activities ...........................................................23

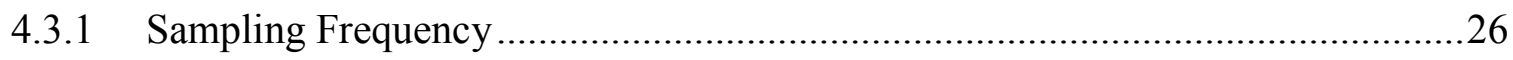

4.3.2 Modify the Daily Implementation Plan ....................................................27

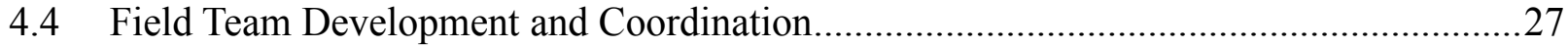

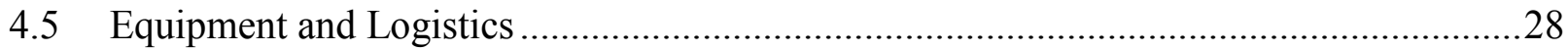

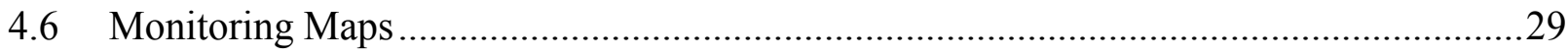

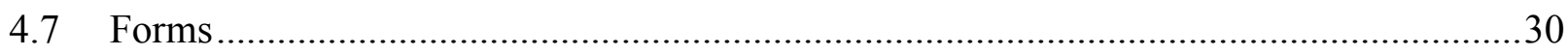

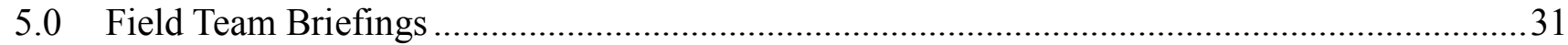

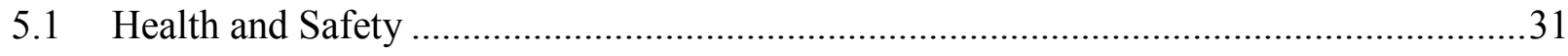

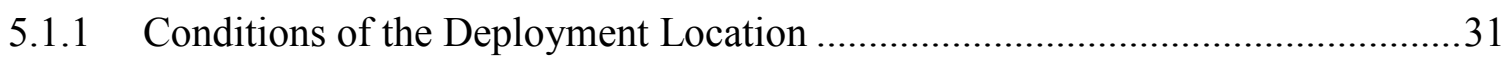

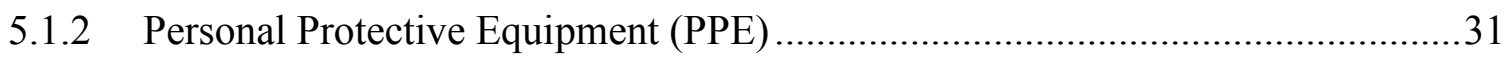

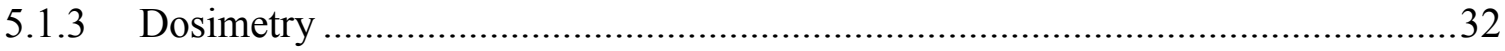

5.1.4 Special Hazard Mitigation Requirements........................................................32

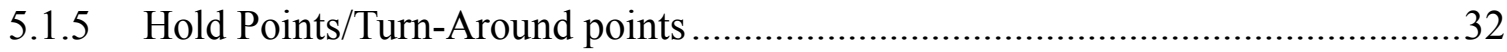

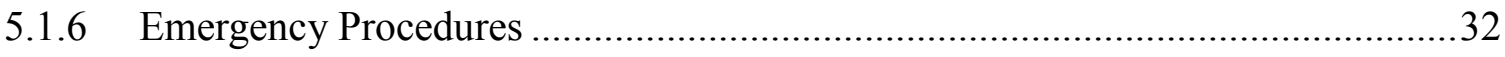

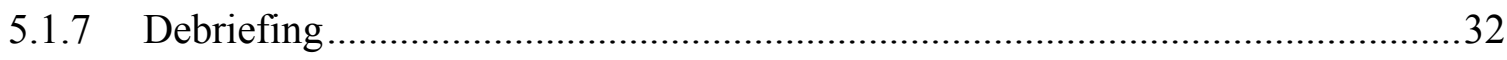

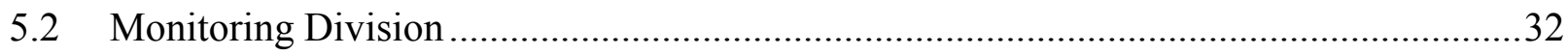

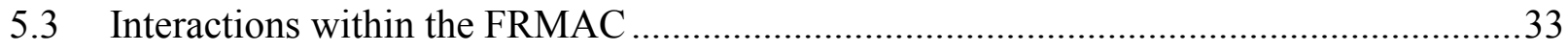

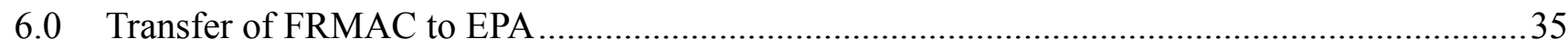

\section{FIGURES}

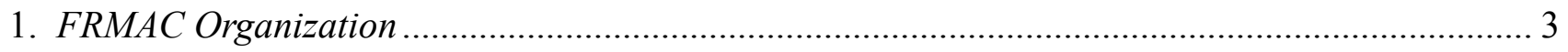

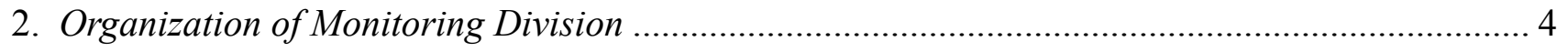

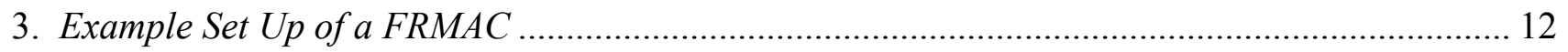

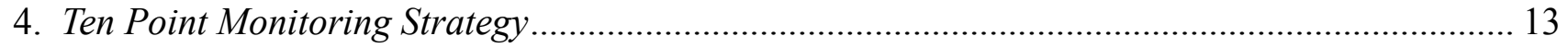

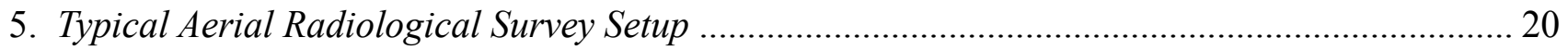

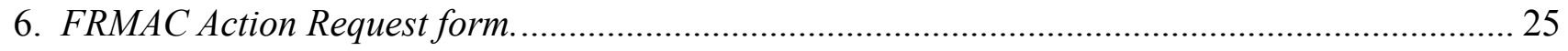




\section{TABLES}

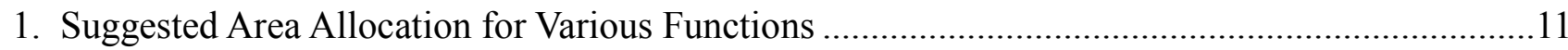

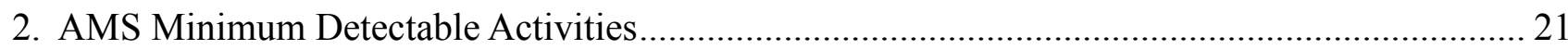

\section{APPENDICES}

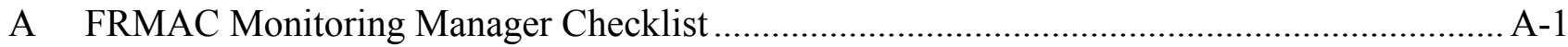

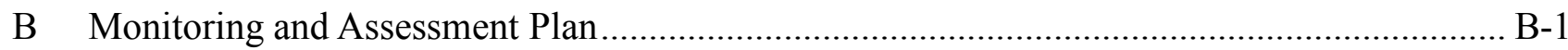

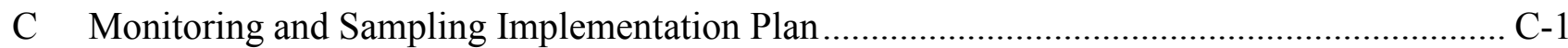

D Monitoring Division Personnel Qualifications and Responsibilities...................................... D-1

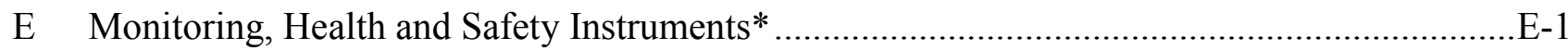

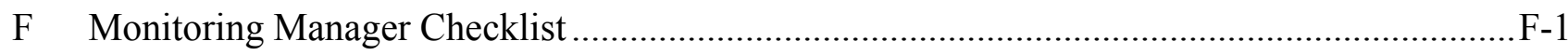

G Monitoring \& Sampling Unit DQO Checklist ....................................................................

H AMS Mission Scientist Checklist …………………....................................................

I AMS Home Team Scientist Checklist................................................................................

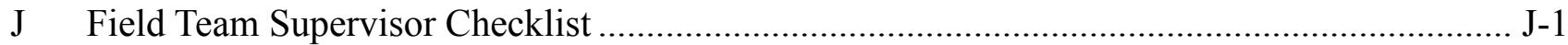

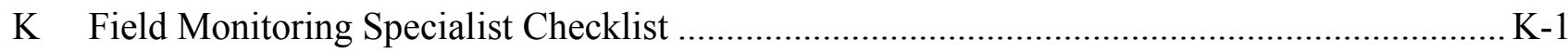

L Health \& Safety Officer Checklist .......................................................................................

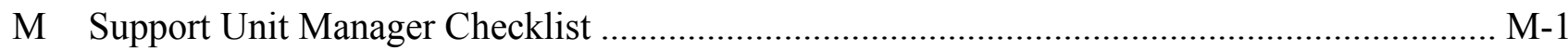

N Support Manager Communication Leader Checklist.......................................................... 
This page intentionally left blank 


\subsection{INTRODUCTION}

\subsection{Role of the Monitoring Division in the FRMAC}

The Monitoring division is primarily responsible for the coordination and direction of:

- Aerial measurements to delineate the footprint of radioactive contaminants that have been released into the environment.

- Monitoring of radiation levels in the environment.

- Sampling to determine the extent of contaminant deposition in soil, water, air and on vegetation.

- Preliminary field analyses to quantify soil concentrations or depositions.

- Environmental and personal dosimetry for FRMAC field personnel, during a Consequence Management Response Team (CMRT) and Federal Radiological Monitoring and Assessment Center (FRMAC) response.

Monitoring and sampling techniques used during CM/FRMAC operations are specifically selected for use during radiological emergencies where large numbers of measurements and samples must be acquired, analyzed, and interpreted in the shortest amount of time possible. In addition, techniques and procedures are flexible so that they can be used during a variety of different scenarios; e.g., accidents involving releases from nuclear reactors, contamination by nuclear waste, nuclear weapon accidents, space vehicle reentries, or contamination from a radiological dispersal device.

A discussion of Standard Operating Procedures (SOPs) for field radiation monitoring and sample collection for use by the Monitoring division during a FRMAC response to a radiological emergency may be found in Volume 2 of the Monitoring Manual—Radiation Monitoring and Sampling.

The Monitoring division also provides technicians to support specific Health and Safety Division activities including:

- The operation of the Hotline.

- FRMAC facility surveys.

- Assistance with Health and Safety at Check Points.

- Assistance at population assembly areas which require support from the FRMAC.

When Monitoring team members are selected for tasks some will be assigned to support the Health and Safety division. A more detailed discussion of the Monitoring division's role in the Health and Safety division may be found in Section 5.1 of this manual.

\subsection{Duties of the Monitoring Division Manager}

The Monitoring Manager works closely with the FRMAC Manager and the Assessment Manager to determine the need for field measurements, sampling, and radioisotope analyses. The Monitoring division's 
operations are then prioritized accordingly. The Monitoring Manager is responsible for ensuring that the radiation measurements, environmental samples, and results from analyses meet the data quality objectives established during the emergency. State and local agencies are encouraged to integrate resources with the FRMAC in their monitoring and sampling efforts; however, the Monitoring Manager is responsible for coordinating monitoring activities to minimize duplication of efforts and assuring compatibility of results if these entities state and local agencies choose to conduct separate operations.

One of the most important duties of the Monitoring Manager in the early stage of the response is to participate in the Advance Party Meeting to establish communication with the various federal, state and local response organizations, and assists in setting sampling and monitoring priorities and strategy for responding to the radiological incident.

The Monitoring Manager must also work closely with the Health and Safety Manager to share information, personnel, and resources.

The Monitoring Manager will be required to provide situation reports to the FRMAC Manager during the response. The report will typically include the status of monitoring activities, availability of field teams and progress on the IAP for the next Operational Period.

The FRMAC Monitoring Manager Checklist may be found in Appendix A of this manual. It is important that the Monitoring Manager utilize this checklist to ensure that all the relevant information has been supplied which will be required to complete the Monitoring and Assessment Plan.

\subsection{Organization of the Monitoring Division}

Figure 1 illustrates the organizational structure of a FRMAC and illustrates how the Monitoring Division fits into the overall FRMAC organization. 


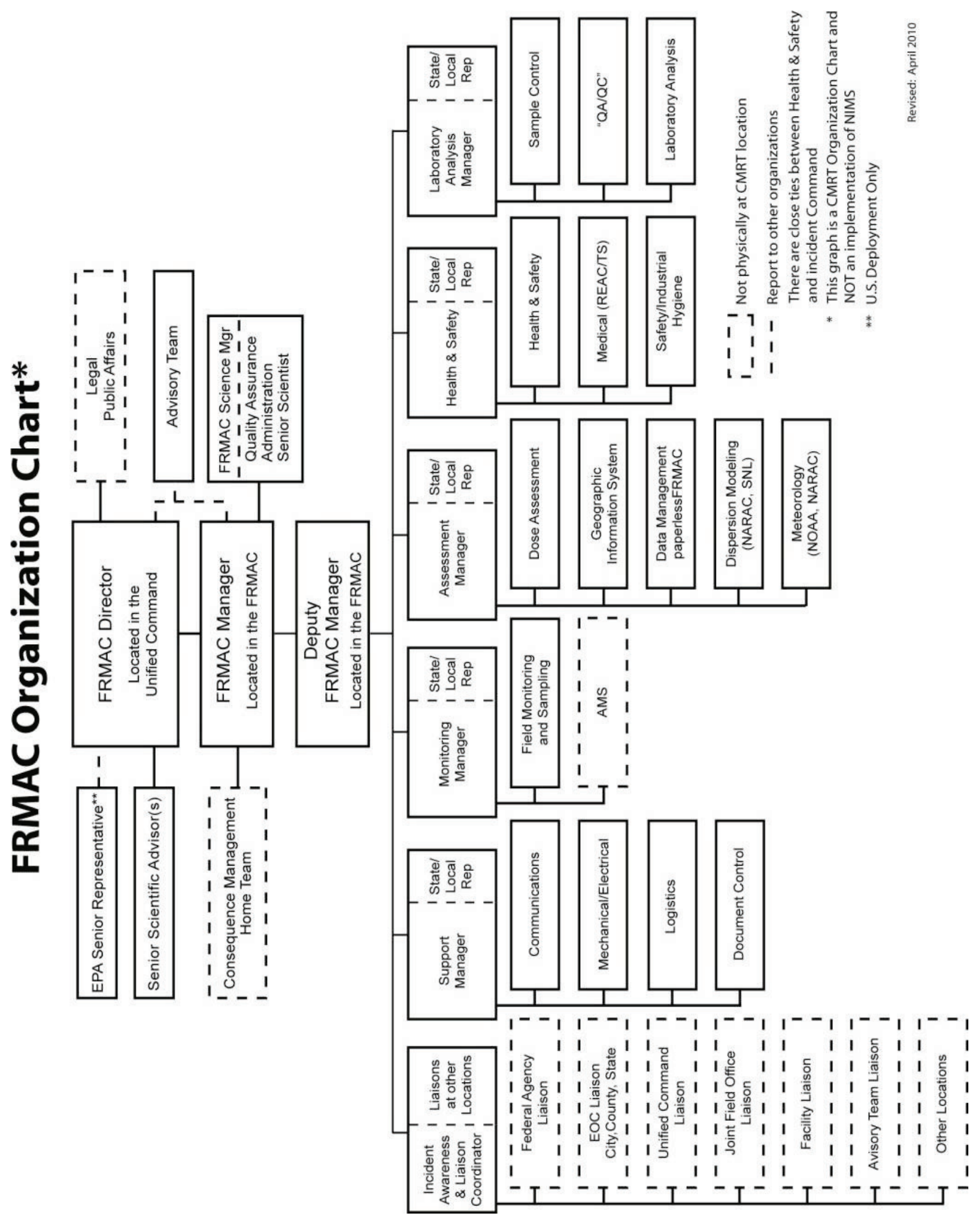

Figure 1. FRMAC Organization 
Figure 2 illustrates the organization of the Monitoring division.

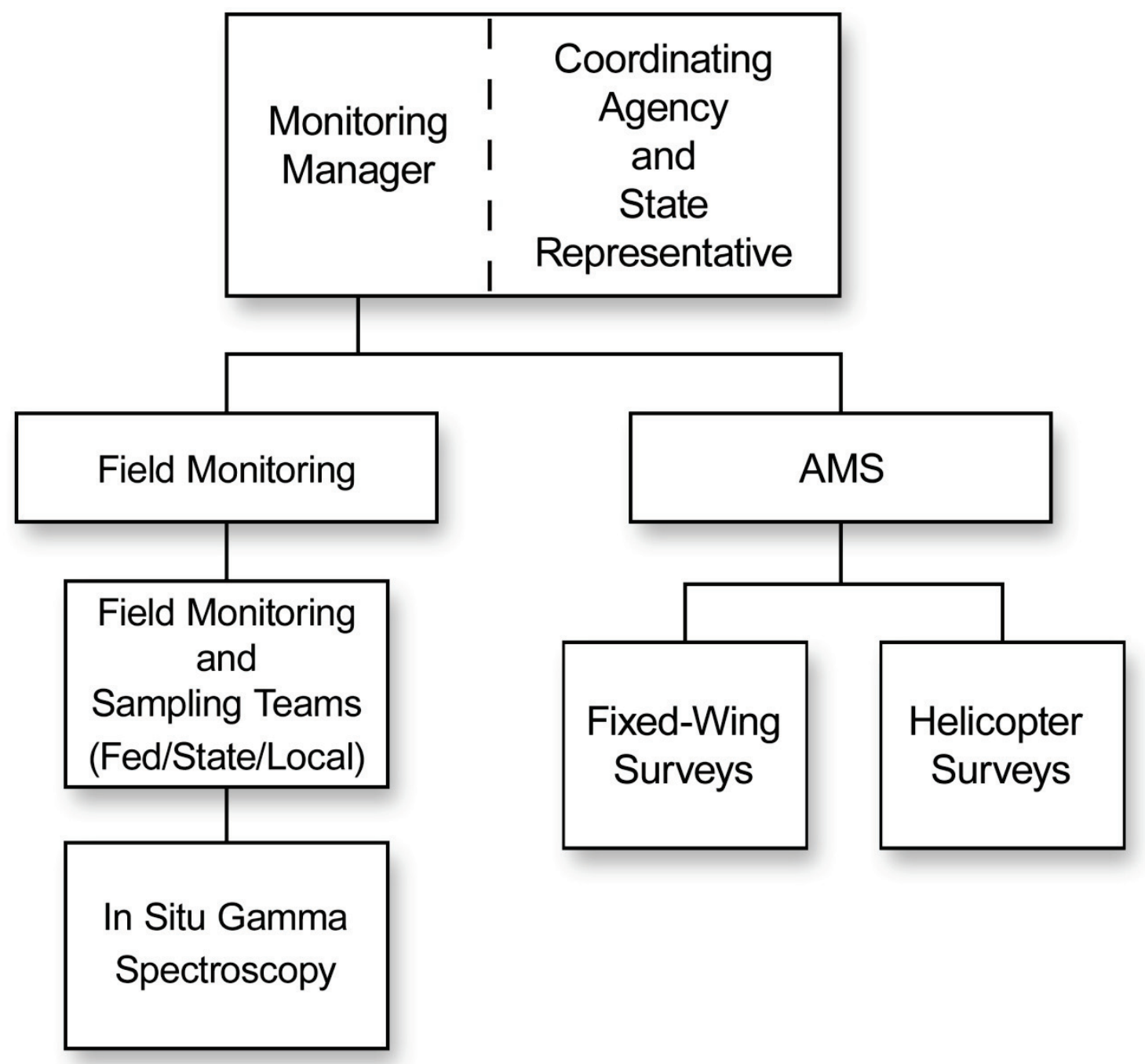

Figure 2. Organization of Monitoring Division 


\subsection{DEPLOYMENT ACTIVITIES}

\subsection{CMRT Phase I Deployment}

The FRMAC Phase I structure provides a phased approach for deployment to start ground and aerial monitoring as quickly as possible to support public safety decisions. The Phase I deployment provides initial data to help reduce avoidable dose and guide evacuation and shelter-in-place decisions.

The Phase I team is expected to integrate any deployed RAP team members and SEO. The RAP SEO integrates with the local Incident Command (IC) and briefs the Phase I FRMAC Manager and Monitoring Manager on IC objectives and any Incident Action Plans currently in effect.

The Monitoring Manager and Field Team Supervisor, along with six Field Monitoring Specialists, deploy with the CMRT I. Once the team arrives on site, the Field Team Supervisor will begin to organize field teams, set up preliminary team routes, and make duty assignments while the Monitoring Manager is participating in the Advance Party Meeting (APM) or IC planning activities. To facilitate this, the Monitoring Manager and Field Team Supervisor should travel together and use the NARAC plots, CMHT information and other available data to preplan field monitoring and sampling routes for use upon arrival.

The teams will receive a safety briefing containing default turn back limits and other key safety and logistic related topics. The Field Team Supervisor will brief the teams on all available information about the release and then inform each team about their route assignments and activities.

The initial plan is to survey for alpha, beta, and gamma radiation. Ideally, one survey site should be selected to collect an air sample for contamination resuspension to allow the assessment scientists to work from field data instead of modeled data. At this resuspension site, the team will take alpha, beta, and gamma surveys and collect an in situ spectrum (if possible), a high volume air sample, and a soil sample.

Once the Monitoring Manager returns from the APM, the Monitoring and Sampling Plan, the Implementation Plan, and new field team routes are developed. The deployed field teams will be recalled, if necessary, or the next shift will work from these approved plans and routes.

\subsubsection{CMHT Support}

In the event of a CM/FRMAC response, a primary role of the CMHT is to support the FRMAC incident response while CMRT I is en route to the incident scene and to provide support to the Radiological Assistance Program (RAP) responders or state or local first responders who may already be on scene gathering early data. CMHT support includes collecting early Radiation Data from the on-scene Emergency Response Teams and entering that data into the RAMS database. The CMHT assists in analyzing data, evaluating hazards, providing incident information and data products to protective action decision makers. The Remote Sensing Laboratory (RSL) serves as the operations center for the CMHT. The CMHT provides a telephone bridge line 
for decision makers, scientists, state authorities, and other assets to discuss the situation and any available data before CMRT I has set up the FRMAC or in the event the FRMAC is not requested. The CMHT will continue to support the incident for as long as necessary.

CMHT support to the Monitoring division may include the following:

- Obtaining the initial National Atmospheric Release Advisory Center (NARAC) prediction model from Lawrence Livermore National Laboratory (LLNL).

- Collecting and analyzing data from the local first response teams to the incident scene.

- Collecting and analyzing data from deployed RAP teams.

- Preparing an Advance Party Meeting Checklist.

- Planning missions for AMS aircraft.

\subsection{CMRT Phase II Deployment}

Two additional Monitoring Managers and one Field Team Supervisor will be added to the deployment roster, along with 12 additional Field Monitoring Specialists with the CMRT Phase II. The additional Monitoring Managers provide additional supervision to develop missions for Aerial Measuring System aircraft and coordinate all monitoring field activities with the Unified Command (UC), the IC Planning Section and the IC Operations Section including an Air Operations Branch director, if applicable. The additional Field Team Supervisor may be assigned to the Health \& Safety Manager to oversee the hotline operation or may assist the monitoring manager with deployment of additional field teams and QA of incoming field data. The additional Field Monitoring Specialists may be assigned to integrate multi-agency field teams or may conduct contamination surveys at the hotline for personnel, vehicles or sample control.

\subsection{CM/FRMAC Forward Monitoring Post}

The CMRT's resources can only establish one FRMAC. A large-area deposition would create an extended area of contamination that would require monitoring teams to travel excessive distances from the FRMAC. CM management and the CMHT would evaluate monitoring activity priorities and may set up Forward Monitoring Posts (FMP). The FMP would be staffed as resources arrive and would operate in coordination with direction from the FRMAC. 


\subsection{INITIAL FRMAC ACTIVITIES}

\subsection{Priorities and Activities}

Monitoring data results and assessments are reported to the Unified Command (UC), the Advisory Team, and the state, tribal, and local governments by FRMAC. In turn, the UC, state, tribal, and local governments will use this information to determine if new or additional protective actions are necessary. The highest priority for FRMAC activities is to protect the public's health and safety. Therefore, the needs of the UC and/or the state, tribal, and local governments dictate the priorities for radiological monitoring and assessment activities. There will be times, particularly in the early stages of a response, when the demand for information and assistance may exceed FRMAC's resources. If that happens, monitoring priorities must then be established.

Following an incident that results in the releases of radioactive material into the environment, the priorities generally focus on determining:

- The extent of the release.

- If the release has been terminated.

- If secondary processes are still dispersing the radioactive material out to a wider area.

- How the release is affecting the population.

- Which populations have been evacuated or sheltered-in-place.

- Safe areas through which people can be transported.

- How long before people sheltered-in-place can be relocated from a contaminated area.

- What are the impacts to critical facilities or infrastructure

\subsubsection{Advance Party Meeting (APM)}

The APM was originally created with the operational objective that a physical meeting would take place with federal, state, tribal, or local authorities once the FRMAC is established or arrives on scene. A formal meeting between all local and FRMAC management personnel may be limited or impractical due to situational constraints. As an alternative, the CMHT may complete the APM objectives using phone or teleconferences while the Phase I team is in transit. The pertinent information from these calls is forwarded to the Monitoring Manager.

The Monitoring Manager will use the FRMAC Monitoring Manager Checklist (see Appendix A) to document all the pertinent information which has been disclosed in the APM. This information will be used to prepare the Monitoring and Assessment Plan.

The APM is extremely important, not only because it initiates large-scale response activities to characterize the extent of the radiation in the offsite area, but also because it sets the tone for interaction between the various response agencies. However resources are integrated or activities coordinated, it is important to open effective lines of communication and to understand the needs of Unified Command to allow for the early establishment of a cooperative relationship. 
The APM should take place as soon as practical upon arrival at the response scene. The FRMAC Director, FRMAC Manager and other technical resource specialists such as the Assessment Manager, Monitoring Manager, possibly the Health and Safety Manager, representatives from state/local response organizations, the Coordinating Agency and the deployed RAP Team Leader meet at the APM.

During the APM the following actions will occur:

- Identify the UC structure and state/local advisors to the Monitoring Division.

- Identify counterparts and liaisons.

- Determine the status of the radiological incident.

$>$ Is a plume still being generated?

$>$ Is there any information on the radiological constituents?

$>$ What are the size and locations of exclusion zones around the incident?

$>$ What is the location of first responders (e.g., RAP team, HAZMAT, CST, etc.)?

- Identify the protective actions that have taken place, or are taking place, in the off-site area (the Monitoring division generally requires a hard copy, including an illustrative map, especially for the evacuated and sheltered areas).

- Identify the ongoing monitoring and sampling activities that will be completed by the time FRMAC is operational (offsite and onsite).

$>$ What analyses are the samples undergoing?

$>$ What is the estimated time before sample analysis results will be available?

$>$ Can FRMAC obtain copies of the monitoring and sampling data - when and how?

$>$ What is the status of the fixed-wing AMS mission and data, if applicable?

- Identify and obtain adequate maps (for field teams and the Monitoring division status map coordinator).

- Identify the location of pre-established state, local, and facility offsite monitoring locations.

- Identify local populated areas and critical facilities such as hospitals, nursing homes, and prisons.

- Identify locations of surface drinking water supplies and open-air water treatment facilities.

- Determine if state, local, and/or facility monitoring personnel will integrate their resources with FRMAC:

$>$ If they will not integrate with the FRMAC, determine who the state contact is for coordinating monitoring, sampling, and analytical activity.

> If state, local, and/or facility monitoring personnel integrate with FRMAC, determine allowable exposure levels and dose commitments. These values, which may be much different from FRMAC values, must be respected. This is also applicable to local law enforcement individuals provided to drive monitoring vehicles.

$>$ Ideally, a FRMAC monitoring team will be comprised of at least three members: one participant who is trained in FRMAC procedures and equipment, one participant who is familiar with radiological instruments and their reporting units, and one participant who is familiar with the local area (that may or may not have technical training in radiological activities). 
- Determine if, when, and how federal first responders will be folded into the FRMAC. If earlier assigned duties take precedence over integrating with the FRMAC, all parties will still be contacted and updated on activities.

$>$ RAP team (status and location).

$>$ Fixed-wing AMS airplanes (status and location).

- Determine the transportation issues for CM/FRMAC monitors to travel in and out of evacuated areas in order to perform monitoring duties.

$>$ Location of roadblocks/checkpoints.

$>$ Authorizations or badges required for entry into areas, facilities, military bases, etc.

$>$ Traffic flows and estimated travel times.

- Identify local and/or facility personnel, familiar with the area, who are available to drive CM/FRMAC monitoring vehicles.

- Prioritize the monitoring and sampling activities that have been requested by the various agencies.

\subsubsection{Interaction with State, Local, Tribal, or Other Federal Agencies}

The Monitoring Manager will need to establish contact with the first responders on the scene to learn what surveys and monitoring activities have been completed. These first responders may integrate with the FRMAC or continue separate, but coordinated, activities as the incident unfolds. Other key contacts will be local law enforcement and/or state officials who may be required to escort field teams to various offsite areas to perform their duties.

In the event that the local response organizations performing monitoring, sampling, assessment, and mapping duties and the FRMAC are not integrated, it is important to establish a means of communication to allow the coordination of activities among the divisions. For example:

- Exchange liaisons within the technical areas to assist in coordinating planning.

- Hold daily planning meetings or conference calls to plan each day's activities.

- Exchange the developed daily activity plans to allow modifications to plans to minimize duplicated efforts.

Following the APM and after considering all the priorities listed above, as well as the answers to the questions addressed at the APM, the Monitoring and Sampling Plan will generally contain some or all of the following points or priorities:

- Assess the footprint to determine the area of radiological concern.

- Assess contamination run-off due to precipitation/resuspension or migration due to winds or mechanical disturbances.

- Identify location of and characterize access control points.

- Survey main transportation corridors to determine if they can be reopened.

- Identify areas that have not been evacuated but where early heath effects are possible (e.g., 100 Roentgen Equivalent Man [rem] in four days). 
- Identify areas that have not been evacuated, but where the Protective Action Guide (PAG) for evacuation may be exceeded (greater than 1 rem in four days).

- Determine the isotopic ratios following a deposition.

- Establish air sampling stations to measure resuspension and future plume releases.

- Monitor institutions, facilities, and/or residences located in the evacuated zone which were not evacuated or where people must reenter.

The FRMAC is there to assist the requesting agency and organization with characterizing the incident and to provide the data needed to make recommendations to mitigate these effects. It is therefore important to establish the customer's requirements at this meeting, and there must be open discussion between the UC and state, local, and tribal concerns and consideration of their views regarding the highest initial priorities that need to be addressed in the Monitoring and Sampling Plan.

\subsection{Site Selection and Set-up}

The CMHT and the CMRT I will coordinate with the local officials who will provide the most assistance in selecting the facilities to support the response. In most instances, a facility will have been selected and the logistics requirements identified by the time the CMRT I team arrives with equipment. The CMRT I Operations Specialists will direct much of the actual layout.

To most effective carry out its mission, whenever possible, a FRMAC will be located within 16 to 24 kilometers (10 to 15 miles) of the emergency scene. Because of the expected use of the NNSA's Aerial Measuring System (AMS) assets, the FRMAC location should be convenient to an airport or a helicopter pad to facilitate rapid data turnaround. Specific site specifications are situation dependent and will vary in accordance with the level of the response. The following is a description of the site requirements that may typically be required for each of the phased response elements. It is important to keep in mind, however, that these requirements are incident dependent.

Important factors to consider when setting up are the placement of Monitoring division assets in the facility and the space needed to perform the work of the divisions. The table below reflects suggested area allocation for various functions of the group. 
Table 1. Suggested Area Allocation for Various Functions

\begin{tabular}{|l|l|}
\hline Activity Requirements & Floor Space \\
\hline General floor space for FRMAC facility & $10,000 \mathrm{ft}^{2}$ to $20,000 \mathrm{ft}^{2}$ \\
\hline Field Team Activities & $1500 \mathrm{ft}^{2}$ \\
\hline Forward Hotline & $500 \mathrm{ft}^{2}$ \\
\hline Sample Storage and Supplies & $500 \mathrm{ft}^{2}$ \\
\hline Sample Receipt & $500 \mathrm{ft}^{2}$ \\
\hline Contaminated Vehicle Storage & $1000 \mathrm{ft}^{2}$ \\
\hline Status Map and Net Control & $250 \mathrm{ft}^{2}$ \\
\hline Data Control & $100 \mathrm{ft}^{2}$ \\
\hline LN, Equipment Storage, Setup & $300 \mathrm{ft}^{2}$ \\
\hline
\end{tabular}

In addition to the floor space requirements, adequate table space, desk space, phone support, and power are required. The Monitoring division should be near an exit (preferably a large dock area) near the parking area. This will allow outside resources to be near the division so field monitoring team preparation, sample receipt, hotline activities, and contaminated equipment storage can be addressed. An area to store and dispense liquid nitrogen (LN) needs to be identified to support the in situ units. The LN area must have adequate ventilation.

A number of mobile laboratories, primarily from the EPA, may be positioned adjacent to the FRMAC building. The total area outside the FRMAC building will be evaluated to include the staging of the mobile labs, field team vehicle parking and equipment storage. The remaining area for FRMAC staff parking spaces may be impacted.

Monitoring division personnel assigned to support the Health and Safety Division will set up some outside resources, such as sample receipt and the hotline. Set up will be determined by the area available and will vary based on factors such as traffic/personnel flow, mobile lab placement, and other organizational needs. 


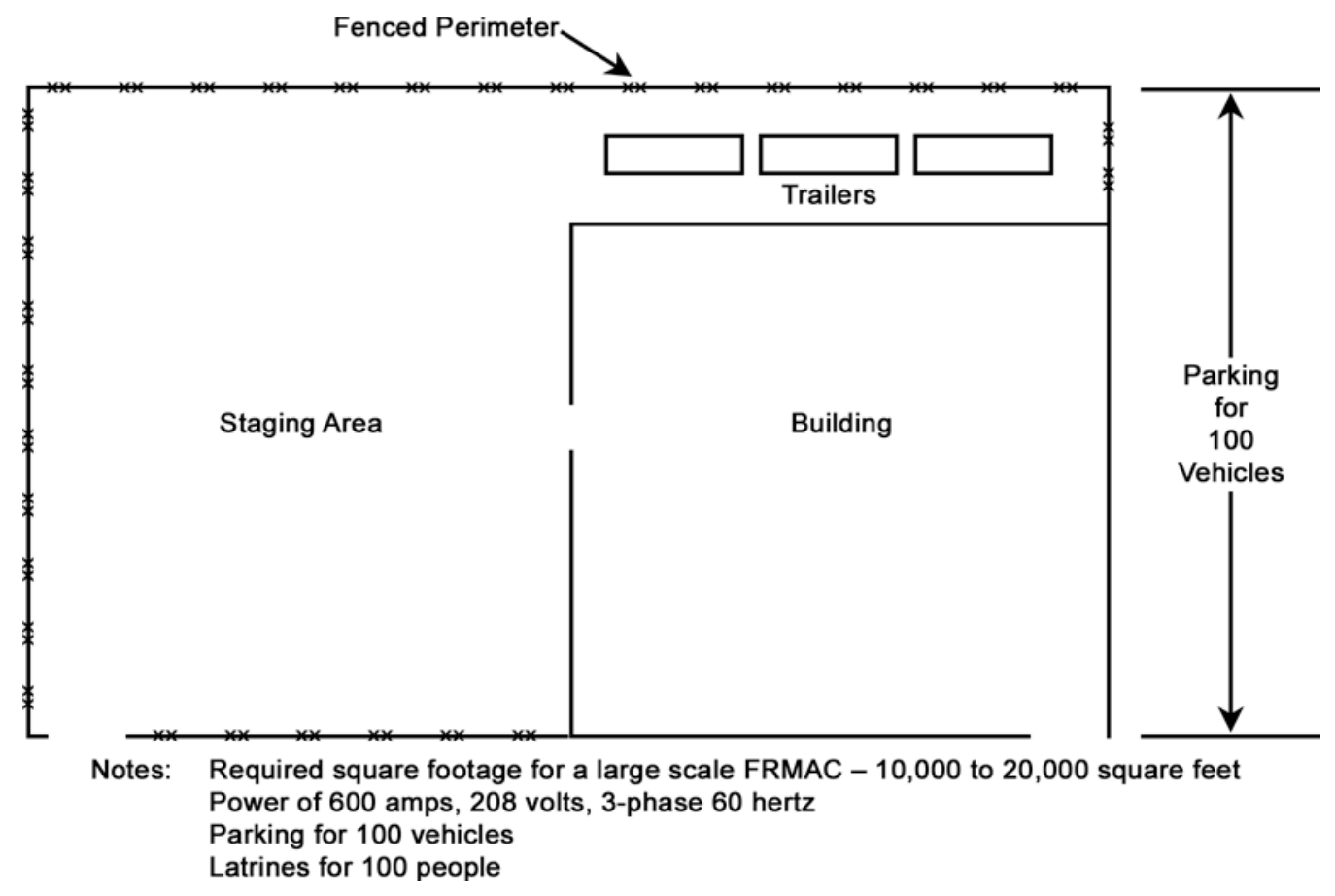

Figure 3. Example Set Up of a FRMAC

\subsection{CMRT Phase I Initial Monitoring Team Deployment}

To allow quicker deployment of field team deployment, the Field Team Supervisor will handle the initial team deployments while the Monitoring Manager participates in the Advance Party Meeting (APM) or coordination activities. The Monitoring Manager will provide any additional pertinent information received during the APM to the Field Team Supervisor if it affects the initial planning developed en route from the RSL.

The teams will receive a safety briefing containing default turn back limits and other key related topics. The Field Team Supervisor will brief the teams on all available information about the release and then inform each team about their route assignments and activities.

Once the Monitoring Manager returns from the APM, the Monitoring and Sampling Plan, the Implementation Plan, and new field team routes are developed. Any currently deployed field teams will not be recalled, but the next shift will work from these approved plans and routes. 


\subsubsection{Ten Point Monitoring Strategy}

Initially structure surveys to cover all types of radiation. Even in a known incident, there may be surprises, especially in the early phase of an incident. It is better to document some negative data than to rush into an unexpected hazard. Once the initial surveys prove the absence of a type of radioactive constituent such as alpha emitters, modify the Implementation Plan to address the actual hazards. Note that many first responders have been issued gamma exposure rate instruments only and may not be capable of surveying for alpha/beta contamination. Although every incident is different, data from the same kinds of measurements may be used to resolve issues; for example, dose and exposure rates, etc.

The Ten Point Monitoring Strategy is a standardized methodology for quickly gathering required radiological monitoring information after a potential release. The strategy is intended to be used during the early postincident phase and will allow quick normalization of computer plume models to match actual release measurements. The strategy is not intended to guide selection of monitoring activities for follow-on cleanup and site restoration tasks.

To execute the Ten Point Strategy, the initial responders should gather radiological monitoring data for the 10 points shown in Figure 4. Conditions or local terrain may prevent access to some of the 10 points. If that occurs, responders should collect as many of the 10 points as possible. The CMHT can help initial responders to select the 10 points using the latest NARAC model runs and the GIS to provide map coordinates or street intersections.

In the following diagram, the distance between the downwind arcs is 1 kilometer and the arc is 30 degrees. The radius of the inner circle is 500 meters. The exact location of each point is not critical, but attempts should be made to be reasonably accurate. The strategy includes six points directly downwind and four on the outer 30 degree arcs.

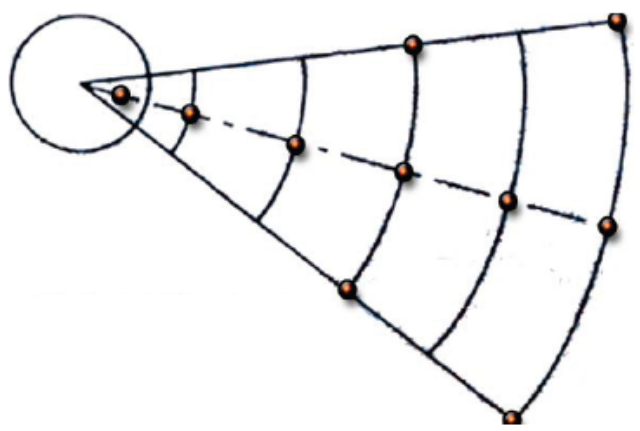

Figure. 4. Ten Point Monitoring Strategy

After some or all of the data are gathered, the CMHT assessment scientist should evaluate the data and request normalization of initial plume plots based on the data.

This strategy will allow a quick comparison of real-world data to plume projections to be made and allow responding personnel to provide effective recommendations on protection of responders and the local population. 
This page intentionally left blank 


\subsection{DEVELOPING AND IMPLEMENTING THE MONITORING AND AsSessment Plan}

The Monitoring and Assessment Plan must be written to address the response elements required to meet the priorities established at the APM. Always plan for what is needed for the response, not what assets might be available. Think of the resources as unlimited since this plan will guide actions throughout the response as more and more resources become available. An example Monitoring and Assessment Plan is included as Appendix B.

Initial incident information could come from several sources including AMS, NARAC, RAP, onsite monitoring resources, and other state/local teams already on scene. The Monitoring Manager must collect all of this information, work with all the parties present at the APM, and devise a monitoring plan for the situation. The plan will be based on the priorities agreed to with the Coordinating Agency, state, tribal and local representatives.

The Monitoring and Assessment Plan is a generic plan that provides a path for completing the priorities set down during the APM. The plan should list the equipment and radiation monitoring techniques used to accomplish the priorities listed. (See Appendix B for a sample Monitoring and Assessment Implementation Plan.)

The Monitoring and Assessment Plan will outline the types of surveys (e.g., contamination vs. exposure rate) and provide the reporting units that the field monitoring teams should use to submit their monitoring results for alpha, beta, and gamma. The plan will list the types of samples the teams should collect and a frequency for collecting them. Collect samples at pre-determined trigger levels based on the DQOs developed by Monitoring, Assessment and Sample Control personnel.

The finalized, approved Monitoring and Assessment Plan will seldom change during the response unless conditions change drastically enough to cause a re-evaluation of the response. The Monitoring and Assessment Plan provides the guidance used to develop daily Implementation Plans that more precisely direct the monitoring division to characterize the radiological incident. The FRMAC Director and staff assigned to the Unified Command ensure that radiological monitoring priorities and resources that are established for the daily Implementation Plan are incorporated into the Incident Action Plan as it is updated throughout the Incident Command planning cycle.

Implementation Plans will include AMS flight operations. However, in many cases, the CMHT and DOE/NNSA plans and approves the first flight since the CMRT will probably be en-route as this planning takes place. Once the AMS assets have completed the first survey flight, they will check in with the Monitoring Manager for subsequent missions, if required.

The FRMAC Manager will direct which agencies have approval authority for the plan. At a minimum the FRMAC Manager, FRMAC Director and the Senior Energy Official (SEO) will approve the plan. If the 
response includes representatives from the Coordinating Agency, the state(s), tribal or local representatives, they may be included in the plan approval.

\subsection{Rationale of Methodology Based on Incident}

The priorities set down during the APM or by the IC objectives or IAP — and the resources available to the FRMAC - drive the factors to consider when developing the Monitoring and Assessment Plan. It is important to remember that resources become available to the FRMAC in a phased manner and that the priorities need to be addressed with available resources.

\subsubsection{Early Phase}

During the early phase of the incident, the DQO requirements for analytical data needed to support assessment have higher MDAs and higher error bar ranges at first but analytical precision requirements increase over time. The sample chain-of-custody is established and maintained although the preliminary logistical support for sample collection, packaging, and transport to analytical laboratories may limit the number and type of samples submitted. DQOs are adjusted to be commensurate with the urgency of the decision at hand, and the risk of potential consequences from an incorrect decision. The relative role of field measurements, mobile laboratories and fixed laboratories will depend on the radionuclides of concern for the specific incident or emergency. (See Appendix G for a sample Monitoring and Sampling division DQO Checklist.)

\subsubsection{Intermediate Phase}

The intermediate phase will require a greater degree of data quality as longer-term exposure risks are evaluated, as well as the use of a formal sample chain-of-custody processes to ensure the data remains legally defensible. These more rigorous DQOs may require the use of fixed laboratories, with greater capacity and enhanced capabilities. The role of on-site analytical capability may also decline depending on its capacity and ability to adapt to these more rigorous DQOs.

\subsubsection{Ability to Detect Key Radionuclides Using Field Instruments}

Another key factor that influences the number of laboratory samples is whether field instruments readily detect the radionuclides in the mixture (or at least some key radionuclides):

- In the situation where some of the key radionuclides are readily detectable using field instruments, the number of laboratory samples can be significantly reduced. In this situation, laboratory samples may be required to supplement the field measurements to verify the overall mixture or to verify how the mixture is changing either spatially or temporally. Once the dynamics of the mixture are confirmed from the laboratory analysis, the vast majority of the data used to characterize the plume will be the results from field instrument measurements.

- In the situation where none of the key radionuclides are readily detectable using field instruments, the number of laboratory samples will be significantly increased. In this situation all of the data used to characterize the plume will be generated from either fixed or mobile laboratories. This situation will result in many hundreds to many thousands of samples being collected and analyzed. To accomplish the priorities, the following strategies should be considered: 


\subsubsection{Ability to Detect Continuous Plume or Waterborne Releases}

a. To sample and characterize areas downwind of a plume release, place gamma monitors with telemetry, air samplers, and thermoluminescent dosimeters (TLDs) at representative locations between the incident scene and populated areas. All three devices should be at each monitoring location, if possible. Emphasis should be given to the prevailing wind direction if it is known.

Note: The monitoring manager shall consult with the FRMAC and UC health and safety personnel to confirm that no non-radiological hazardous constituents are in the plume that could create Immediately Dangerous to Life or Health (IDLH) conditions for the monitoring teams.

b. Place additional gamma monitors, air samplers, and TLDs at representative populated areas.

c. Based on information received from the monitoring aircraft and the meteorological conditions, deploy monitoring teams to travel roads in the vicinity of the incident site looking for the plume.

d. Each team should be equipped with plume sampling and radioiodine analysis capability. Teams should traverse assigned areas until contact is made with the plume. The team will operate the air sampling equipment and conduct hand-held measurements as they transect across the plume path.

e. Teams monitoring water pathway should obtain appropriate and representative water samples. These samples should be obtained from streams, rivers, estuaries, bays, and other bodies of surface water.

\subsubsection{Deposition Measurement by Ground Teams}

Identify isotopic mix and verify deposition models by taking appropriate radiation measurements using available roadways to traverse the predicted footprint. The chosen roadways and flight paths should intersect a representative number of predicted radiation contours. The routes should generate additional data points to supplement the initial ten-point monitoring survey results, if applicable. The monitoring strategy for the routes and spacing of survey locations should include:

- Input from the Assessment and Laboratory Analysis Divisions on the types of data and sampling requirements.

- Input from Assessment and GIS on the spacing of data points relative to the ground deposition contours and map scale for the various briefing products. For most incidents, the spacing for deposition surveys can vary from hundreds of feet near the release point to many miles between data points down range where the deposition is more uniform.

- Input from the health \& safety officer regarding traffic barricades into the exclusion zone and the location of vehicle and personnel hotline exits from the exclusion zone. In addition, local law enforcement may exclude ground survey teams from some areas due to safety issues.

Depending on the type of radiological release and the suspected source term, some basic rules of thumb can be applied: 
- Gross alpha and beta measurements will provide many more data points per total survey time if there has not been any appreciable precipitation or weathering of the deposition. The monitoring and assessment managers need to concur that a gross alpha or beta measurement is a sufficient surrogate result for a key constituent.

- In situ gamma spectrometry systems are the preferred field-team instrument to be used with an exposure rate meter to confirm the gamma-emitting constituents in the deposition footprint. The number of field in situ measurements should be planned to limit total exposure to the ground team members. An alternate strategy is to use the in situ system as a soil or vegetation sample counter to determine ratios and decay, if applicable.

- Also as a rule of thumb, soil and vegetation samples should be collected at every order-of-magnitude change in measured radiation levels. The assessment and laboratory analysis division should specify minimum and maximum exposure rate screening levels for samples to be returned from the field for subsequent analysis.

\subsubsection{Deposition Measurements by Aircraft}

One emergency response asset available to the Monitoring Manager is the use of AMS aircraft to perform flyover surveys of the incident site. AMS has both fixed wing and helicopter mounted survey equipment that can fly over a deposition site at various altitudes to determine ground deposition area and levels. Often AMS aircraft will be requested very early in a response and may have already acquired data that will be beneficial to the Monitoring division. The AMS group will often write, review, and get approval for the initial mission plan at the Remote Sensing Laboratory (RSL) located on Nellis Air Force Base, Las Vegas, Nevada, or Andrews Air Force Base in Maryland. Additional AMS aircraft can be deployed from the Savannah River Site, South Carolina or by the EPA based in the Kansas City, Kansas area. Subsequent mission plans will be developed by the FRMAC AMS mission scientist before review and approval by the Monitoring Manager and Health and Safety Manager. The mission plans can then be incorporated into the Implementation Plan. The AMS Mission Scientist will utilize the AMS Mission Scientist Checklist when developing the mission plan (see example checklist in Appendix H).

The fixed-wing aircraft and helicopter require the use of a fixed base of operations (FBO) facility to conduct aerial survey missions. In most responses, a commercial or military airport will be used for deployment. The FBO facilities will be chosen by the AMS flight crew based on their relative distance from the incident area and the availability of commercial electrical power, aviation fuel, and telephone and Internet services.

For many scenarios, the AMS aircraft will not be located near the FRMAC facility. The mission scientist and Pilot-in-command will receive directions from the FRMAC monitoring manager through commercial telephone, satellite phone systems, or from the CMHT. Most of the AMS data products will be submitted to the FRMAC via the CMHT after they have been transmitted via the aircraft telemetry systems or after postflight data processing and Internet transmittal from the FBO.

For the fixed-wing system, the nominal survey altitude is 305 meters $(1,000$ feet $)$ above ground level with flight line spacing of approximately 500 meters (1,600 feet) at a ground speed of 72 meters per second (140 knots). At the nominal altitude of 1,000 feet, the fixed-wing field of view is approximately 2,000 feet in width. At the nominal mission altitude and field of view, the fixed-wing can coarsely map ground deposition at a rate of about 39 square kilometers per hour (15 square miles per hour). The primary fixed-wing data 
products include a map product of the gross count data points and a contour map product display of the nominal exposure rates at 1 meter above the ground. The data processing time required to complete each set of flight data is approximately 1-2 hours. The ground monitoring field teams should not expect the exposure rate levels produced from the flight to match those during ground deposition transects. In addition, the deposition boundary defined by the fixed-wing aircraft may only be accurate within a few hundred feet.

For the helicopter system, the nominal survey altitude is 46 meters ( 150 feet) above ground level with flight line spacing of 92 meters ( 300 feet) at a ground speed of 36 meters per second ( 70 knots). The preferred aerial platform for performing a detailed aerial survey is the helicopter because of its larger-volume $\mathrm{NaI}[T 1]$ detector array, lower flying altitude, and greater spatial resolution. A map produced from helicopter data provides much more detailed information for decision makers.

The higher sensitivity and line spacing used for radiological mapping surveys allows the data to be contoured in the units (counts, exposure rate, man-made) necessary for comparison to long-term guidance levels. Flying at an altitude of 46 meters (150 feet) will provide a ground-monitoring window (field of view) of approximately 92 meters (300 feet) in width. In this manner, the helicopter can map the ground deposition at a rate of about 10 square kilometers per hour (4 square miles per hour). The radiological survey flights are normally limited to daylight hours. However, nighttime flights will be considered on a case-by-case basis. (see Figure 5).

- After each survey flight, detailed data analysis is performed with the computer analysis equipment on site. The data processing time required to complete each set of flight data is approximately 1-3 hours. Completed survey deliverables are:

1. Contour map of inferred exposure rate at one meter above ground level, and

2. Contour map(s) of specific isotope surface area activity identification, and magnitude of dominant isotopes (gamma energy spectra).

- The minimum detectable activity limits of the AMS aerial platforms for a typical radiological survey are shown in Table 2. Sensitivity values are given for typical isotopes in units of microcuries per square meter $\left(\mu \mathrm{Ci} / \mathrm{m}^{2}\right)$, assumed to be surface deposition with no mixture in the soil. Detection sensitivities will vary, depending upon altitudes flown, line spacing, deposition variability, and analysis processing. 


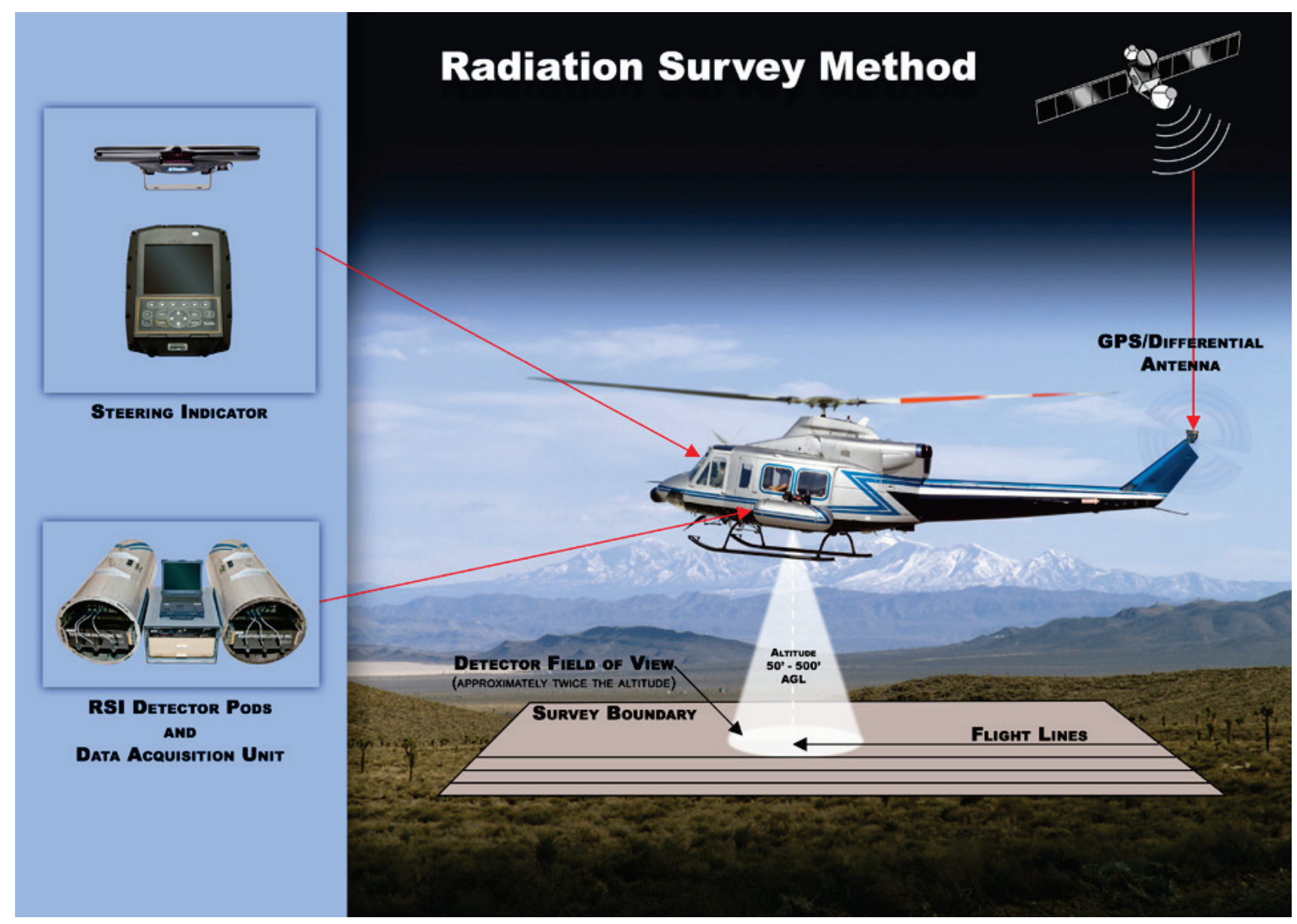

Figure. 5. Typical Aerial Radiological Survey Setup 
Table 2. AMS Minimum Detectable Activities

\begin{tabular}{|l|c|c|c|}
\hline & \multirow{2}{*}{$\begin{array}{c}\text { Photopeak } \\
\text { Energy } \\
\text { Radionuclide }\end{array}$} & $\begin{array}{r}|c| \\
\text { (kiloelectron } \\
\text { Volts }[\mathrm{keV}])\end{array}$ & $\begin{array}{c}\text { Furface Area Deposition } \\
\left(\mu \mathrm{Ci} / \mathbf{m}^{2}\right)\end{array}$ \\
\cline { 3 - 4 } & Aircraft $^{\mathbf{b}}$ & Helicopter $^{\mathbf{c}}$ \\
\hline $\begin{array}{l}\text { Americium-241 } \\
\left({ }^{241} \mathrm{Am}\right)\end{array}$ & $60 \mathrm{keV}$ & 430 & 0.2 \\
\hline Cesium-137 $\left({ }^{137} \mathrm{Cs}\right)$ & $662 \mathrm{keV}$ & 2.0 & 0.05 \\
\hline Cobalt-60 $\left({ }^{60} \mathrm{Co}\right)$ & $1,173-1,333 \mathrm{keV}$ & 0.3 & 0.02 \\
\hline Iodine-131 $\left({ }^{131} \mathrm{I}\right)$ & $365 \mathrm{keV}$ & 4.0 & 0.06 \\
\hline
\end{tabular}

${ }^{\text {a }}$ Minimum detectable activity (MDA) value is the three-sigma value due to the counting statistics in the spectral energy window of the photo peak of interest.

${ }^{\text {b }}$ Fixed-wing systems are equipped with one 2 -inch by 4 -inch by 16 -inches $\mathrm{NaI}(T 1) \log$ flown at an altitude of 305 meters (1,000 feet) above ground level, a flight line spacing of 500 meters (1,600 feet), and an average ground speed of 72 meters per second (140 knots). Flying at higher altitudes (e.g., 1,500 feet) will reduce detectability by a factor of 3 or more.

c Helicopter systems are equipped with eight to twelve 2 -inch by 4 -inch by 16 -inch $\mathrm{NaI}(T 1)$ logs flown at an altitude of 46 meters (150 feet) above ground level, a flight line spacing of 92 meters ( 300 feet), and an average ground speed of 36 meters per second ( 70 knots). Processing the data using a 9-second averaging routine can enhance the detectability up to a factor of 3 .

\subsubsection{Monitoring of Shelter-In-Place Locations}

Based on the aerial monitoring and meteorological data, monitoring should be initiated in the downwind direction from the plume footprint. Monitor where people are residing in the non-evacuated areas. Continue monitoring for 360 degrees. Attempt to monitor along the edge of the inhabited zones closest to the evacuated areas. Place representative, continuous particulate and reactive gas air samplers and TLDs in these close-in inhabited areas to measure resuspension, integrated exposure, and possible future plume releases. The actual placement of the samplers should be determined by the number of samplers available, population distribution, and local wind conditions. The following types of facilities usually have electrical power available and are "good" places to locate air samplers:

- $\quad$ Fire and police stations

- County and state road maintenance facilities

- $\quad$ Schools and public park facilities

- City, county, and state municipal buildings

- Hospitals 
If none of these facilities is available, attempt to locate the samplers at service stations, convenience stores, or residences. As a last resort, use the portable generators to supply the electrical power for the samplers.

\subsubsection{Monitoring of Critical Institutions, Facilities, Transportation Corridors and Residences Where People Must Reenter in the Near Future}

Critical transportation corridors and facilities may be in use throughout the entire response. Numerous repeated surveys may be requested as local authorities attempt to decontaminate the roads and facilities used for evacuation and response teams.

Monitoring efforts in facilities must be coordinated with state and/or local officials in order to mitigate the impact to evacuation and response efforts. When tasked to survey non-evacuated facilities, monitoring teams should be accompanied by local uniformed police or firemen. It is necessary to monitor the exteriors of the structures as well as the interiors. Interior monitoring will include the acquisition of swipes from representative surfaces. Environmental TLDs should be placed inside and outside of each occupied structure. Representative individuals at each location should be assigned a TLD to wear. If available, gamma-rate recorders should be placed inside the structures. The appropriateness of locating particulate and reactive gas air samplers at these stay-in locations should be determined. A brochure describing basic facts about radioactivity and exposure reduction techniques for inhabited structures should be distributed.

\subsubsection{Site Characterization}

For monitoring and sampling activities for an NRC-related incident, the Monitoring division may use the U.S. Nuclear Regulatory Commission (NRC) sector divisions of the off-site area (16-22.5-degree sectors). If the FRMAC response is other than an NRC-related incident, the Monitoring division can create survey grid maps oriented about the incident site by using FRMAC GIS capabilities. In addition, the EPA may provide guidance on data requirements for the late phase recovery and clean-up operations expected after the incident has been stabilized. To characterize the area and to identify hot spots, at least one monitoring team should be assigned to each survey grid. If practical, monitoring activities should be initiated at a distance well beyond the deposition footprint and moved in toward the incident center. As a monitoring team travels within their assigned grid, a serpentine pattern will be followed using available roads as safe vehicle travel allows. The sites where representative radiation measurements are taken should include all pre-established state, local, and facility monitoring locations. Soil and vegetation samples should be collected at each order-of-magnitude change in the radiation field measurements or as directed. At representative locations, including within the evacuated areas, a continuous air sampler and an environmental TLD should be positioned. Together, they will provide a measure of re-suspension and integrated radiation exposure at that location. These will complement those placed near the evacuated/inhabited areas.

\subsubsection{Drinking Water}

In coordination with state and/or local officials, drinking water samples should be collected from surface supplies and open-air water treatment facilities located in the affected areas. It would be expected that the typical alpha, beta and gamma measurements will be taken adjacent to any water treatment facilities to document the probable surface deposition after plume passage. 


\subsubsection{Farms, Dairies, and Food Processing Plants}

The monitoring and sampling of farms, dairies, and food processing plants will, in all likelihood, be conducted at the request of state or local officials. If no priorities or requests are received, the FRMAC should consider the following:

- Farms and dairies within the deposition footprint will receive last priority for Monitoring division resources, since contamination is assumed to have occurred based on their location and their products have been embargoed immediately after the deposition has been confirmed.

- Farms outside of the deposition footprint will be monitored in order of the perishability of crops.

- Milk, food, and animal feed processing facilities outside the evacuated area will be monitored and sampled in order of their priority within the operational IAP.

\subsection{Develop Daily Implementation Plan}

Once the Monitoring and Assessment Plan is completed and approved, a plan must be devised to implement it. The Implementation Plan is completed daily or for each operational period and describes in greater detail the techniques and resources that will be used to characterize the incident. The Implementation Plan will address each of the priorities and the techniques listed and explain how the Monitoring division will complete the task.

Many things will affect the daily plan and change the response. New priorities may be introduced based on survey data that is collected during the previous day's activities. Various agencies will refine their requests for information or priorities will shift due to public concerns and the Implementation Plan needs to be flexible enough to accommodate those shifting priorities. An example Implementation Plan is included as Appendix C.

\subsection{Specific Monitoring and Sampling Activities}

The Implementation Plan will be the guide for selecting monitoring team makeup and provide guidance for performing the actual monitoring and sampling to the teams. The plan will specify the surveys to be taken, the survey techniques to be used, the routes to take, and the frequency at which the surveys will be taken.

The plan will specify where and when samples will be collected, the duration of air samples, and the location of environmental thermoluminescent dosimeter (TLD) placement. The plan will outline the equipment requirements for the teams and the support that will be provided to the other sections of the FRMAC such as Sample Receipt and Health and Safety support.

The required surveys will be based on the type of release. Ground surveys near the expected plume or deposition area are normally spaced closer together than those further away. One major reason for the close spacing is to reduce the chance of the team missing a turn-back level and receiving an unnecessary dose. Another reason is the possibility of missing the boundaries of the deposition. If surveys are spaced too far apart it is possible to drive into or through the contamination or even traverse the plume completely. 
In the first hours of the response, the emphasis will be on establishing the type and amount of radioactive contamination in the area and whether there is any resuspension in the air from the ground deposition.

Follow-on teams can more completely characterize the distribution of the radioactive material in the environment.

Routes for the monitoring teams will be developed using the best available information on the incident release. These will include NARAC plots and AMS fly over data, on-site monitoring, and off-site results gathered by first responders. The routes developed will depend on the priorities of the situation. Generally, the first routes established will verify the NARAC models to define the edges of the deposition and to begin defining evacuation routes or shelter-in-place locations for the public. Additionally routes will be developed that collect air, soil, water, and vegetation samples at locations throughout the affected area.

As part of the Implementation Plan, personnel and resources may be assigned that do not perform monitoring and sampling duties. Personnel may be assigned to support the Health and Safety Division by setting up a hotline at the facility or to staff checkpoints in the field. Decontamination stations may be required at various locations and these would be managed in accordance with the Implementation Plan. Personnel may also be assigned to support the facility or the field teams as runners for sample recovery or to distribute needed supplies to the field.

Teams are dispatched with maps, equipment, and instructions on how to accomplish the tasks outlined in the plan. As the field teams collect survey data and samples and report the results back to the FRMAC, a clearer picture of the situation will develop. This information will necessitate changes to the Implementation Plan or prompt other agencies to request additional survey or monitoring information. The Monitoring Manager will be required to look at these evolving needs and incorporate them into the Implementation Plan.

The prescribed tool for other agencies to make requests to the Monitoring division is the FRMAC Action Request form (Figure 6). Action Requests are submitted to the FRMAC Manager and prioritized for distribution to the appropriate division for action. Action requests are handled according to the priority of the request and not the order in which they are received. Urgent requests will generally be handled as soon as possible or the same day. Routine requests will generally be written into the next day's Implementation Plan unless they can easily be incorporated into current activities or covered by a team that has completed their planned activities. The Monitoring Manager must look at the request and see how it can be rolled into the current Implementation Plan and redirect the resources necessary to do that. 


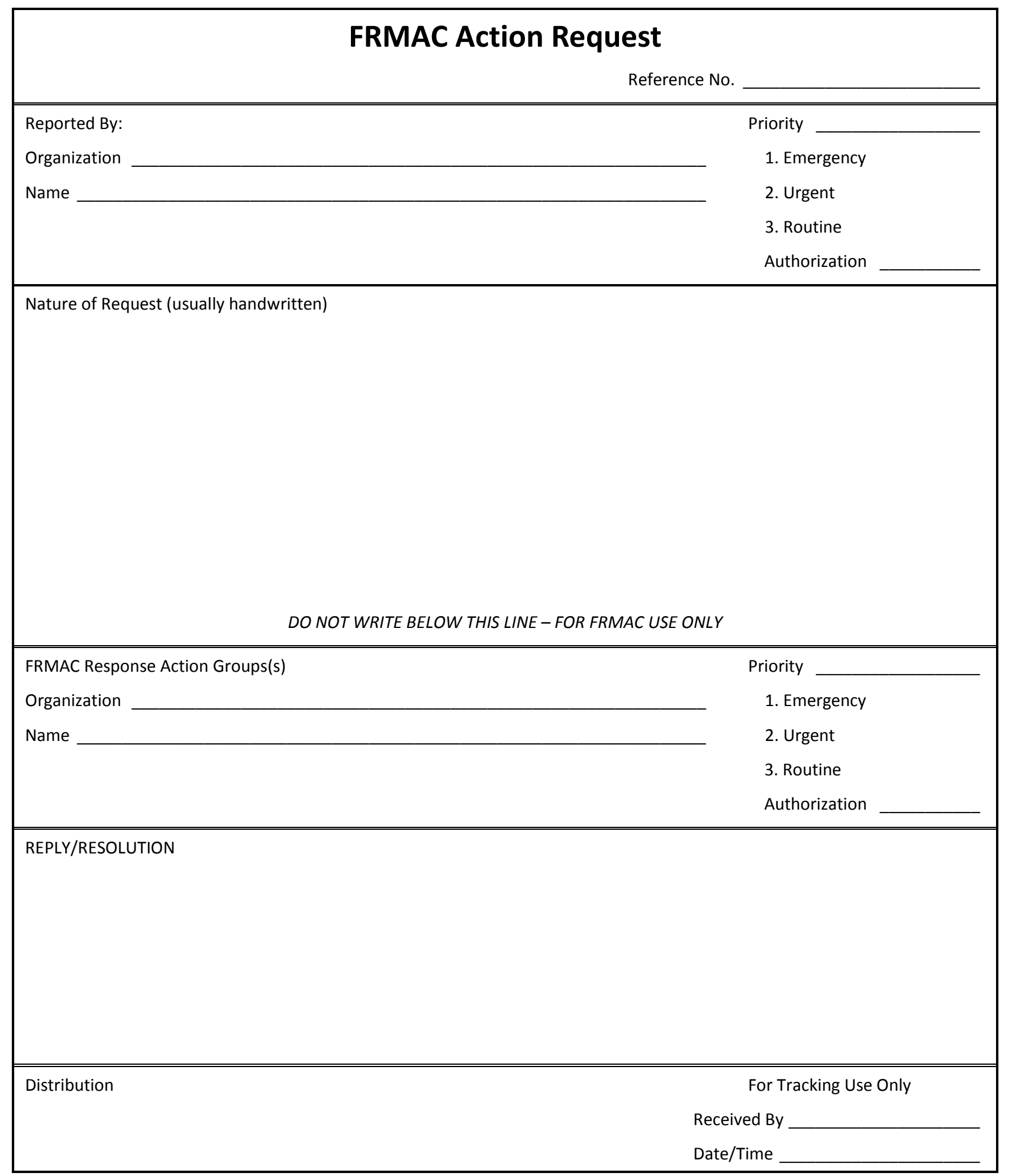

Figure 6. FRMAC Action Request form. 


\subsubsection{Sampling Frequency}

\section{Air Sampling}

Particulate and reactive gas samples and whole air samples for noble gas analysis are exchanged daily. In most situations if samplers are in operation when a plume release occurs, the samples will be changed out following plume passage.

The run times for the various high-volume and low-volume air samplers will be established with the Assessment and Laboratory Analysis divisions. Some of the parameters include:

- Radionuclide mixture

- Contamination levels and an initial resuspension factor estimate

- Weather conditions - primarily wind speeds and direction and the precipitation forecasts during the sampling period

- Minimum and maximum radioactivity to be collected on the sampling media

- Projected run-times from batteries or portable generators if commercial power is not available.

\section{Water Sampling}

Community surface drinking water supplies and open-air water treatment facilities located within the deposition footprint should be sampled following passage of the plume and resampled daily. Daily sampling should continue until usability of the water is determined (i.e., does it meet drinking water standards or is it a non-flowing body of water sufficiently contaminated that it cannot be used as a drinking water supply for some period of time).

Community surface drinking water supplies located outside of the deposition footprint but in the proximity should be sampled daily for a minimum of three days or until acceptable levels are achieved. Sediment samples will be collected from surface drinking water supplies located within the deposition footprint and re-sampled as required.

\section{Note On Collecting Samples:}

Care should be exercised in collecting environmental samples. The radioanalytical laboratories can be easily inundated. A sufficient number of samples must be collected to characterize the environment and to satisfy monitoring requirements, but the collection of samples should be performed prudently.

\section{Vegetation Sampling}

The purpose of FRMAC vegetation sampling is to measure deposition, not plant uptake. In almost all radiation emergencies, leafy vegetables retain deposited contamination and may be a health problem if consumed.

The two major types of samples collected include:

Market ready food is directly ingested by the populace. Market ready vegetation samples will come from farms, roadside stands or gardens. Market ready samples should be consistent with respect to readiness for harvest. Either the crop is already ripe or will be ripe and ready for harvest in the near future. 
Feed crops are hays and grains that will be consumed by animals and subsequently man will consume the animals. Typical products include standing grains (wheat, rye, barley, buckwheat, oats, and soybeans) and standing hay. The sample results are categorized as pasture deposition measurements. Samples may be taken from unsheltered baled or stacked hay or stored feed if these are being used as feed for animals.

\section{Milk Sampling}

Following a single release containing radioiodine, the radioiodine will begin to appear in the milk of exposed cows and goats in 3-4 hours. The radioiodine concentration will attain a maximum in approximately three days. For these reasons, milk sampling should begin the day after the plume passes. If milk from a particular dairy is to be characterized, sampling should begin with the first milking after the plume passes and continue daily. When the milk is collected, samples of the animals' feed and water should also be collected.

Note: From the same exposure, goat's milk will have radioiodine concentrations four times greater than those in cow's milk.

\section{TLDs}

The lower levels of detection for personnel and area TLDs are approximately $0.1 \mathrm{mSv}$ and $0.1 \mathrm{mGy}$ (10 mrem and $10 \mathrm{mRad}$ ), respectively. The TLDs should be deployed for a sufficient length of time so that meaningful data that meet FRMAC objectives are produced.

\subsubsection{Modify the Daily Implementation Plan}

The Implementation Plan is a fluid document and will change almost daily. As field teams complete or expand surveys in one area or additional requirements are placed on the division the plan will change. A new Implementation Plan is completed for each day's activities. Each new plan will still be guided by the original Monitoring and Assessment Plan but will include the new information gathered, the new requests made, modify the survey routes, and redirect resources as needed to complete the mission. Implementation Plan development is synchronized with the Unified Command planning cycle as the radiological monitoring and sampling priorities evolve within the Incident Action Plan. As each plan is modified, reports will be generated for the FRMAC Manager explaining the tasks that have been completed, what is still incomplete, and what priorities are being established for the incomplete tasks.

\subsection{Field Team Development and Coordination}

Actual deployment of personnel and resources will be dependent on the severity of the incident. During a CMRT I deployment only six technicians are available for field teams to cover initial 24-hour operations. Ideally each field team will consist of three persons. If no local assistance is available, then the teams will be comprised of two persons until additional resources can be assigned.

One of those six technicians functions as the Field Team Supervisor (FTS). The FTS assists the Monitoring Manager by coordinating the teams and equipment while the Manager is working on the plans necessary to get the teams into the field. He/she also ensures that paperwork is complete and given to Document Control 
in the FRMAC prior to deployment. The Field Team Supervisor will utilize the Field Team Supervisor Checklist (shown in Appendix J) to ensure that all tasks have been addressed.

With additional resources, more teams become available. If arrangements were made during the APM, state, tribal, local, and regional personnel should be available to the Monitoring Division. A three-person team is considered ideal with one member from DOE/NNSA, one EPA or another organization with technically trained personnel, and one local person who knows the area. Two person teams are capable of completing assigned tasks but could be hampered by trying to navigate through new areas, watch the road for hazards, and keep an eye on instrumentation when in or near the plume deposition area.

When selecting teams, the relative experience of the team members should be considered. It is optimal to have a mix of experienced and less experienced people on a given team. A listing of Monitoring Team positions and the required knowledge and skills is presented in Appendix D and a checklist outlining the tasks assigned to Field Monitoring Specialists is presented in Appendix K. Also, it is important to remember that different organizations may have different ALARA (As Low As is Reasonably Achievable) limits. When forming teams the most restrictive limits of an organization on a team will be the guide. If a situation arises where limits may need to be exceeded, the organizations would need to grant approval or a different team will be used to complete the task.

In a CMRT II deployment, a team will typically consist of the following personnel:

- Field Team Leader

- Team Member/Information Recorder

- Navigator/Escort (state, tribal, or local representative)

- In situ operator, if required

\subsection{Equipment and Logistics}

Equipment for the FRMAC is also deployed in two phases. The table in Appendix E lists the instrumentation and personal protective equipment (PPE) that are available in each phase. All of this equipment is inspected, maintained, and calibrated on a regular basis. All equipment will arrive ready for immediate use.

An important consideration is that other agencies may also be responding to the radiological emergency and would be incorporated into the FRMAC. Due to the vast variety of instrumentation available and in use throughout the country there is no way to know what could be incorporated into the response. However, it is important to gather from the other agencies the instrument calibration data for each instrument. Also any correction factors or other information that will aid in the interpretation of readings collected with the instrument in the field should be known. This information may not be immediately available, but it should be obtained quickly.

The Logistics and Support Section of the FRMAC under direction of the Support manager will make vehicle arrangements for the field teams. When possible these vehicles will be mini vans or sport utility vehicles (SUVs) to accommodate the field teams' equipment. A checklist outlining the expected logistical requirements is shown in Appendix M. 
Each team will consist of a minimum of two members or ideally three members plus equipment, but may include additional members such as an in situ technician. The vehicle should be configured to minimize the spread of contamination by covering the seats and floorboards with plastic. The back of the vehicle would be used for storing equipment or collected samples.

In addition, the Support manager is also often responsible for oversight of the teams' communications requirements. A checklist outlining the items relating to communications that needs to be considered is shown in Appendix N.

The field teams will be dispatched with the equipment necessary to complete their mission. The Field Team Leader will need to ensure that the teams have checked out this equipment for proper operation and logged all the equipment on the appropriate forms so that the data they transmit back can be matched to the teams and the equipment they are using.

\subsection{Monitoring Maps}

Field teams will need maps of the area to complete their mission. Efforts will be made to secure as many maps as are available in the local area upon landing. Local airports and car rental agencies are a good source for securing local maps. These local maps can be used to plot routes for the teams.

FRMAC has developed a robust GIS capability to produce electronic map displays. The electronic maps can be used to track the progress of teams back at the FRMAC. Additionally predictive maps of plume deposition are available electronically to assist in briefings prior to sending out field teams. When requested, hard copy maps can be given to the teams since one of the primary missions is to verify the legitimacy of the predictive model.

As the incident progresses additional maps will be created from the data collected by the FRMAC. The data sources can include telemetered data from field team devices, radio transmitted, hard copy and data bases submitted by the CMHT. Radiological Monitoring and Sampling Status Maps are created at least once per operational period. These maps summarize the location and type of all radiological monitoring and sampling data that has been collected up to the current time. The maps should reflect the levels of radiation, concentration, or dose rates.

The Monitoring and Sampling maps are updated frequently by the GIS and displayed electronically within the FRMAC. Because they continually grow in density and diversity of measurements, they provide guidance to the Monitoring Manager and field team supervisors on the performance of the monitoring teams. They can also show gaps in the aerial coverage of data points necessary for modeling to PAGs.

The FRMAC GIS can provide maps that show roadblocks, check points, decontamination stations, and evacuated areas may all be helpful to the various teams in the field. Specific FRMAC monitoring and sampling maps will be given to field teams based on team assignments and routes. It is expected that the GIS electronic and hard copy maps will replace local maps as the response capability expands. 


\subsection{Forms}

Throughout the FRMAC response, it will be important to document everything that is done in order to facilitate information sharing and to provide a record of events. Many forms are used in a response. Listed below are the forms specific to the Monitoring division with a brief explanation of the form's use. Instructions for completing the forms are included on the back of each form and also in Volume II of the Monitoring and Sampling Manual.

- $\quad$ Team, Instrument, and Equipment Information Log: Used to collect team information such as personnel assignments, instrumentation, radios, global positioning system (GPS), and vehicles used by Field Teams.

- $\quad$ Multi Path Communication Device (MPCD) and Data Tablet running Digital Field Monitor program: Used by Field Teams to record data collected in the field.

- $\quad$ Field Monitoring Log: Used by Field Teams to record data collected in the field if MPCD is not available.

- $\quad$ Sample Control Form: Used by Field Teams to record information pertaining to samples collected in the field; serves as the Chain of Custody for the sample as well.

- Daily Instrument Quality Control (QC) Checks: Used to record instrument quality control checks.

- $\quad$ FRMAC Action Request: Used by all agencies to make requests of the FRMAC for tasks.

- Local Area Monitoring TLDs: Used to record pertinent information of Environmental TLDs used in the field.

- Data Acquisition Log: Used by Field Team Contacts to record data called in by Field Teams field if MPCD is not available. This form matches the Field Monitoring Log. 


\subsection{FIELD TEAM BRIEFINGS}

Field teams will be briefed on a daily basis prior to the start of work and departure into the field. A representative of the Health and Safety Division will conduct part of the briefing, focusing on the current health and safety plan requirements. The Monitoring Manager or Field Monitoring Supervisor will complete the briefing for the monitoring objectives and priorities contained in the current IAP. All field team personnel for each shift are required to attend. The type of information to be included in the briefing follows.

\subsection{Health and Safety}

Monitoring needs will vary depending on the emergency, the responding organization(s), and local emergency responders. The staff of the responding organization(s) may be required to operate in a wide variety of settings (in vehicles, in public facilities) and perform various functions, such as:

- Sample collection

- $\quad$ Area monitoring

- $\quad$ Monitoring in vehicles

- $\quad$ Personnel surveys

- In situ measurements

\subsubsection{Conditions of the Deployment Location}

Personnel should be aware of local surroundings. Weather conditions should be presented to personnel at regular intervals and as changing conditions warrant.

Existing radiological, chemical, biological, or other hazards need to be communicated to monitoring teams. It allows them to be prepared for encountering any expected or possible circumstances such as:

- $\quad$ Climate (weather)

- $\quad$ Biohazards (snakes, ticks, etc.)

- $\quad$ Expected radiological contaminants/levels

- $\quad$ Expected chemical contaminants/levels

- $\quad$ Possibility of terrorist activity and use of weapons of mass destruction

- $\quad$ Traffic expected (is the area evacuated?)

- $\quad$ Response of local population

\subsubsection{Personal Protective Equipment (PPE)}

Field teams will be briefed on PPE requirements prior to potential exposure. The teams will be briefed on the PPE to be used for each hazard, as well as when to don and doff PPE, such as anti-contamination (anti-C) clothing and/or respiratory protection. FRMAC deploys with PPE that meets level D or C requirements. Entries into impacted areas that require level A or B PPE require interagency coordination. Appendix E contains a listing of potential PPE that could be used. 


\subsubsection{Dosimetry}

Field teams will be briefed on the dosimetry requirements prior to any potential exposure and a Health and Safety representative will ensure personnel have the appropriate dosimetry, such as:

- Whole body dosimetry

- $\quad$ Supplemental dosimetry

- $\quad$ Neutron dosimetry

- Extremity dosimetry

- Bioassay

- $\quad$ Personal air sampling

\subsubsection{Special Hazard Mitigation Requirements}

Once existing or expected hazards are identified, the methods required to mitigate these hazards must also be communicated and provided. Special clothing requirements for weather conditions should be identified and provided. Local climate conditions should be announced (e.g., roads that flood, roads that freeze, etc.). Traffic conditions and roads to be avoided based on traffic, climate, hazardous and/or radiological conditions should also be noted.

\subsubsection{Hold Points/Turn-Around points}

Turn-around or hold points will be established when the hazard exceeds the level of prescribed protection. Points shall be established for field teams where additional control (such as gloves/boots, anti-Cs, or respiratory protection) will be required. The Health and Safety Manager will determine turn-around points based on expected conditions and risk involved, such as:

- $\quad$ Turn-back levels for radiological, chemical, heat/cold, etc.

- $\quad$ Call-in points

- $\quad$ Access-control points

\subsubsection{Emergency Procedures}

All personnel need to be made aware of emergency response procedures. This includes general reporting of fires or accidents and any unusual activities. Monitoring teams also need to understand proper handling of contaminated victims or materials. Phone numbers for local medical centers and emergency contact information will be provided to all field teams prior to deploying from the FRMAC.

\subsubsection{Debriefing}

Debriefing of participants should be incorporated into the daily routine (at the end of each shift) to capture lessons learned and identify hazards that should be discussed in the next shift's safety briefing.

\subsection{Monitoring Division}

Incident Information: This will cover the status of the incident such as duration and type of release, radioactive constituents if known, and data gathered by on-site or first responders. 
Routes: Maps, expected routes, and route activities will be covered to assist each team in accomplishing their mission.

Special Concerns: Areas that require specific entry/exit requirements based on the nature of the incident (contamination control, sample methods, changes, etc.).

Communication Protocols: The devices, protocols, and frequency for relaying data back to the Technical Operations Centers (TOC).

Public Affairs Information: What and how to communicate with the general public concerning the functions they are performing in the field, and who the public can contact for further information.

\subsection{Interactions within the FRMAC}

The Monitoring Manager must work closely with the Health and Safety Manager to share information, personnel, and resources. The Health and Safety division is responsible for:

- The operation of the Hotline

- $\quad$ FRMAC facility surveys

- Assistance with Health and Safety at Check Points

- Population assembly areas which require FRMAC assistance

- Personnel Protective Equipment Requirement

- $\quad$ Team Turn Back Levels

- Dosimetry Guidelines

- Tracking of estimated doses to FRMAC responders

The Monitoring division provides the technicians to operate these resources. When team members are selected for tasks some will be assigned to support the Health and Safety division.

All the logistical needs of the Monitoring division should be handled through the FRMAC chain of command. Communications, vehicles, and facilities are all handled by the Support Manager.

The Health and Safety division provides for the safety and security of the field teams, so it is important they be kept up to date on information gathered in the field in order to make informed decisions. The Health and Safety Manager may come directly to the Monitoring Manager for specific clarification of data turned into the FRMAC or to request additional personnel and resources to fulfill its mission.

The Assessment division uses the data collected in the field to plot potential PAG level boundaries and to provide decision makers and the Advisory Team information needed to make recommendations. The Assessment division is also responsible for providing the Monitoring division with requests for the types of surveys and samples they require. As with all data collected in the field, these requests are first reviewed by 
the Monitoring Manager and then handed over to Data Control for dissemination to the rest of the FRMAC. Data Control will make copies of all data, file them, and provide copies to the Monitoring division for working up new routes and plans.

The Monitoring Manager will also be required to provide situation reports to the FRMAC Manager during the response. The report will typically include status of monitoring activities.

The quality of the data used as a basis for protective actions is of paramount importance. The resources devoted to quality assurance depend largely on the stage of the emergency. In the early phase of a radiological emergency when the impact on public health and safety is not well defined, the number of FRMAC resources devoted to quality assurance will be sufficient to ensure that data of acceptable quality is available in a timely manner. As the emergency stabilizes, the resources dedicated to quality assurance will increase. 


\subsection{TRANSFER OF FRMAC TO EPA}

The immediate emergency condition as stated in the National Response Framework (NRF) - National Response Incident Action (NRIA) Plan must be stabilized and:

- Offsite releases of radioactive material have ceased, and there is little or no potential for further unintentional offsite releases

- The offsite radiological conditions have been characterized and the immediate consequences have been assessed

- An initial long-range Monitoring and Sampling Plan has been developed in conjunction with the affected states and appropriate federal agencies and,

- $\quad$ EPA has received adequate assurances from the other federal agencies that they will commit the required resources, personnel, and funds for the duration of the federal response.

To facilitate the transfer additional joint DOE-EPA guidance documents have been written. As required under all ICS planning, a FRMAC transition team will be created during the response to work on the process. The process may be included in the Unified Command demobilization section plans.

Note: The EPA will create a FRMAC organizational structure to meet its requirements for a Unified Command to conduct long-term monitoring, environmental clean-up and population resettlement. 
This page intentionally left blank 


\section{APPENDIX A}

FRMAC MONITORING MANAGER CHECKLIST

\section{Federal Radiological Monitoring and Assessment Center (FRMAC) Monitoring Manager Checklist}

\section{Status of Emergency}

1 Type of incident:

a. Time?

b. Duration?

c. What is estimated source term(s)?

d. What are dominant isotopes?

e. What was the meteorology during each release?

$>$ Wind speed and direction:

> Precipitation:

> Stability class:

2. What actions have been taken to stop and/or mitigate the release(s)?

3. Is the situation stable?

4. Are current problems likely to affect areas outside of the exclusion zone?

a. How?

b. When?

5. Status of Emergency Operations Centers (state, local government)

\section{Ongoing Emergency Response Activities}

1. What protective actions have been taken and/or are pending?
a. Estimate of population directly affected.
b. Evacuations in progress/ordered.
c. Shelter locations.
d. Location of decontamination facilities.
e. Status of hospitals. 
2. Are the protective action guides in use the same as those for U.S. Environmental Protection Agency/U.S. Department of Agriculture/U.S. Food and Drug Administration?

3. Are maps delineating the protective actions available?

4. Are atmospheric prediction plots available? Types?

5. What is the current status of monitoring and sampling activities?

6. Is any radio analytical data available?

7. What monitoring/sampling results are available?

8. Identify un-evacuated local special needs populations such as hospitals, nursing homes, and prisons.

9. Identify institutions, facilities, and residences located in the evacuated areas which were not evacuated or must be re-entered.

10. Identify locations of surface drinking water supplies and open-air treatment facilities.

\section{Establishment of Communications and Liaisons}

1. Identify:

a. Primary state radiological decision-maker

b. State/local advisor(s):

$>$ Monitoring

$>$ Health and Safety

> Assessment

2. Are federal responders operating prior to an operational FRMAC (i.e., RAP) to be integrated into the FRMAC?
a. When?
b. How?
c. Who is the contact? 
3. Are local personnel available to drive monitoring vehicles?

4. What procedures are in place to allow FRMAC vehicle and personnel to pass through road blocks?

\section{Integration of Response}

1. Will state/local personnel join the FRMAC?

a. If YES, identify state/local personnel radiation turn back levels and dose commitment limitations.

b. If NO, identify state/local contact for coordinating monitoring and analytical activities.

2. Identify state/Coordinating Agency/local personnel to aid in development of initial FRMAC Monitoring and Sampling Plan.

3. Identify state/local and Coordinating Agency personnel to work with FRMAC Dose Assessment.

4. Identify state/local and Coordinating Agency personnel to work with FRMAC Health and Safety.

5. Determine placement needs for liaison personnel

Integrated Priorities (prioritize state, county, and local concerns)

Rev. 10/11 
Potential Priorities (for consideration during planning)

Assess the footprint to determine the area of radiological concern.

$>$ Determine re-suspension factors

$>$ After deposition, determine isotopic ratios

$>$ Identify hot spots

$>$ Establish air sampling stations to measure re-suspension and future plume releases

$>$ Provide a measure of the validity for the dispersion models in use

$>$ Identify location of and characterize access control points.

Perform surveys of special facilities (Hospitals, Nursing Homes, Prisons, Schools, Food, Drug, Agricultural, etc)

$>$ Identify contaminated areas where people have not relocated and non-contaminated areas where the population can return.

$>$ Identify areas that have not been evacuated, but where early health effects are possible (100 rem in four days; i.e., $1 \mathrm{rem} / \mathrm{h}$ ).

$>$ Identify areas that have not been evacuated, but where the federal protective action guide (PAG) for evacuation may be exceeded (greater than 1 rem in four days; i.e., without knowing isotopic ratios, $10 \mathrm{mrem} / \mathrm{h}$ ).

$>$ Monitor close to evacuated areas where people are located.

$>$ Provide monitoring data to allow decision makers to identify evacuated areas where the public can return.

Perform surveys to determine if the main transportation corridors can be reopened. (This includes highways, surface roads, railroads, water transport, etc.)

Sample surface drinking water supplies and open-air water treatment facilities.

$>$ Assess contamination run-off/deposition (movement of radioactive material.)

Support reentry, cleanup, and mitigation activities

$>$ Support monitoring and decontamination of Emergency Workers and Equipment

$>$ Support monitoring and decontamination efforts for the population

$>$ Support reentry efforts

Rev. $10 / 11$ 


\title{
APPENDIX B
}

\section{Monitoring AND ASSESSMEnt Plan}

\section{Empire 09 (FSE)}

\section{Operational Period 0700 June 03 - June 04, 2009}

\author{
Monitoring \& Assessment Plan Narrative \\ IC/UC Incident Objectives Identified in IAP or IC/UC Action Requests \\ Listed in order of priority.
}

- IAP \# 2, Objective \# 1.

- IAP-Assist state of Vermont field teams to assess potential contaminated areas

- FRMAC - Assess the areas of potential inhalation and ingestion pathways to determine if the area restrictions for radiological concern can be lifted.

\section{Assessment:}

Provide dose assessment and stay times for returning state, county and city residents to their homes in affected areas. Provide assessment for return of residents for normal occupancy. Assess for 50-year EPA protective action guidance. Provide map products illustrating areas of concern. Required measurements or samples include direct measurements for ground deposition of alpha and beta activity, gamma exposure rates, air concentration levels, and radionuclide identification made with an HPGe.

\section{Monitoring:}

Assign two ground teams to supplement existing Vermont assets. Any unexpected radiation levels will be reported immediately. This information will allow a better definition of the problem. Resources will be allocated to conduct initial alpha, beta contamination surveys, gamma exposure rate surveys, and Violinist surveys. Sample collection may include high-volume air, soil, vegetation, water, swipe samples and other samples to better define the contamination levels. Long term air sample locations may be established by the state. Helicopter aerial surveys by AMS will be used to delineate contaminated areas to the extent practical. Identify areas of possible run-off with risk to public and agricultural.

Characterize deposition/exposure foot print: Conduct surveys around any designated facilities.

- IAP \# 2, Objective \# 2.

- IAP - Continue monitoring and sampling activities to valid the extent of contamination and determine appropriate actions 
- FRMAC - Assess the deposition footprint to determine the areas of radiological concern.

\section{Assessment:}

Provide map products illustrating areas of radiological concern. Continue aerial measurements north of I-90 centered on the Hudson River for ground concentration and exposure rate as applicable for Am-241 and Cs-137. Required ground team measurements/samples include direct measurements for alpha, beta, and exposure rate readings. Samples may include soil, water, milk, vegetation and agricultural products.

\section{Monitoring:}

All field teams will complete gamma exposure rate surveys whenever they must travel near or in the plume to determine they are not exceeding their turn back levels. Any unexpected radiation levels will be reported immediately. This information will allow a better definition of the problem. Resources will be allocated to conduct initial alpha, beta, gamma contamination surveys, gamma exposure rate surveys, and Violinist surveys. In situ measurements will be conducted, along with sample collection including; high-volume air, soil, vegetation, water, swipe samples and other samples to better define the plume foot print and contamination levels. Long term air sample locations may be established. Helicopter aerial surveys by AMS are expected to be conducted at $150 \mathrm{ft}$ altitude with $550 \mathrm{ft}$ line spacing to delineate contaminated areas to the extent practical. Identify areas of possible run-off with risk to public and agricultural. Radionuclide ratio evaluations are to include assessment of gamma isotopes, and local staff augmentations to support in situ measurements-

Characterize deposition/exposure foot print. Focus on evacuated areas and adjacent noncontrolled areas. Identify contaminant re-suspension and air concentration levels in the vicinity of the accident site.

- IAP \# 2_, Objective \#_3_.

- IAP - Assess the impact to and plan to restore critical infrastructure

- FRMAC - Assess the radiological concern at critical government centers and facilities to determine if they can be occupied by essential state staff for government operations. Evaluate for normal government staffing and operations.

\section{Assessment:}

Provide dose assessment and stay times for essential state, county and city staff to maintain and operate critical facilities in affected areas. Provide assessment for return of staff for normal government operations at evacuated government centers. Provide map products illustrating areas of concern. Required measurements/samples include direct measurements for alpha, beta, exposure rate readings, air concentration levels.

\section{Monitoring:}

All field teams will complete gamma exposure rate surveys whenever they must travel near or in the plume to determine they are not exceeding their turn back levels. Any unexpected radiation levels will be reported immediately. This information will allow a better definition of 
the problem. Resources will be allocated to conduct initial alpha, beta, gamma contamination surveys, gamma exposure rate surveys, and Violinist surveys. Long term air sample locations may be established. Radionuclide ratio evaluations are to include assessment of gamma isotopes, and local staff augmentations to support in situ measurements-

Characterize deposition/exposure foot print. Focus on evacuated areas and adjacent noncontrolled areas. Identify contaminant re-suspension and air concentration levels in the vicinity of the accident site.

Characterize deposition/exposure foot print: Conduct surveys around the designated facilities.

\section{Albany County:}

Hospitals in and around the evacuated/shelter in place area - especially Memorial Hospital @ 600 Northern Blvd

Albany Medical Center

Memorial Hospital

VA Hospital

St Peter's Clinic

Whitney Young Meth Clinic@10 DeWitt St

Albany Fire Department HQ @ 26 Broad St

Albany FD Hq S. Pearl @ Morton

Albany Fire Station (Arbor Hill)@ Manning Blvd @ Lark Dr

Albany Police Department HQ @ 165 Henry Johnson Blvd

Albany Police Station (South Street) @ 126 Arch St

Albany PD/FD Como

Albany PD Division 2

Albany City Water

Albany Co Sewer

Albany General Services Department (this is the Albany Public Works equivalent) @ 1 Connors Blvd

Albany County Health Department @175 Green St

Albany Co. Office 112 State St. 
Albany Co. Probation

Albany Greyhound Bus Terminal @ 34 Hamilton St

Albany City Offices @ 24 Eagle

Albany County Social Services @ 162 Washington Ave

The Courts to include the Federal Court on Broadway, Court of Appeals on Eagle, and Albany County Court on Lodge. There are many courts. All courts in the affected area are a priority.

Schools - Elementary, Middle and High Schools (if applicable)

NY State Capital @ State St and Eagle St

NY State Social Services @ 112 State St

NYS Comptroller

NYS ES Plaza

NYS DMV

NYS Dormitory Authority

NYS DEC

SUNY Main Office DH Bldg.

National Grid, Albany Facility

Rensselaer County:

Rensselaer City Hall

Rensselaer Fire Department HQ

Rensselaer Fire Station - Broadway

Rensselaer Fire Station - East St.

Rensselaer Fire Station - Partition St.

AmTrak Station

Rensselaer Volunteer Ambulance - 3rd St.

Rensselaer Police Department HQ 
Hudson Valley Community College

All Senior Citizen/Retirement Homes

Schools - Elementary, Middle and High Schools (if applicable)

Rensselaer High School

Donne Stewert School - Washington Ave

Forbes Ave Senior Housing

State Health Facility

- IAP \#_1_, Objective \#_4_.

- IAP - Continue to provide for the safety and welfare of the responders and public

- IAP - Continue monitoring and sampling activities to valid the extent of contamination and determine appropriate actions

- FRMAC - Characterize drinking water sources / supply facilities for Albany and Rensselaer Counties.

\section{Assessment:}

Determine general population internal dose from area drinking water supply. Identify source and distribution.

\section{Monitoring:}

Allocate resources to conduct exposure rate and alpha contamination surveys of areas surrounding the public water supply location(s). Water samples will be taken at each reservoir location, intake and exit points (if applicable). Additional information is needed on the location of the water supply to determine how to approach and sample this location, e.g., its location in relation to the plume footprint, whether it is currently being used to supply surrounding population.

Rensselaer Pump (Sewer) Station

Water Treatment Plants (if applicable)

Cold Water Pumping Stations

- IAP \# 1, Objective \# 5.

- IAP - Establish and maintain effective traffic control measures around the impact area

- IAP - Assess the impact to and plan to restore critical infrastructure

- FRMAC - Characterize Impacts to major Transportation Corridors and Infrastructure. 
Assessment: Provide dose assessment for travels over major transportation corridors. Determine contamination levels and assess potential re-suspension by various transportation systems. Provide dose assessment and stay times for transportation centers (i.e. train stations...) staff and customers for normal operations.

Major and secondary roads north and east of the incident sites.

Railroad@Random Locations

Bridges over the Hudson River

Port of Albany facilities 


\section{APPENDIX C}

\section{Monitoring AND SAMPLing IMPLEMENTATION Plan}

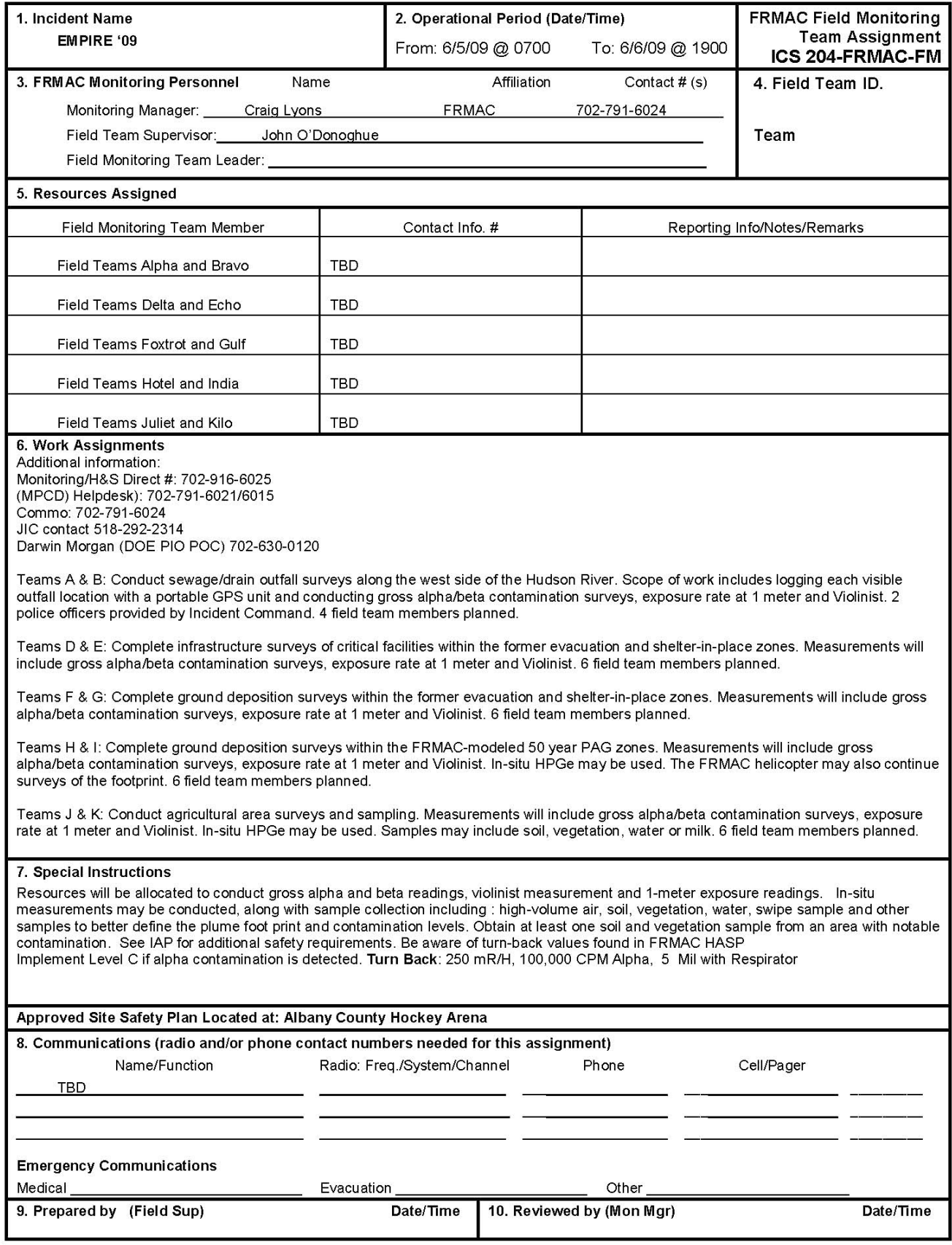

FIELD MONITORING TEAM ASSIGNMENT

ICS 204-FRMAC-FM (Rev 09/07) 
This page intentionally left blank 


\section{APPENDIX D \\ Monitoring Division PERSONNEL \\ QUALIFICATIONS AND RESPONSIBILITIES}

\begin{tabular}{|l|l|l|}
\hline \multicolumn{1}{|c|}{ POSITION } & \multicolumn{1}{|c|}{ RESPONSIBILITIES } & \multicolumn{1}{c|}{\begin{tabular}{c}
\multicolumn{1}{c|}{ KNOWLEDGE } \\
AND SKILLS
\end{tabular}} \\
\hline $\begin{array}{l}\text { Monitoring } \\
\text { Manager }\end{array}$ & $\begin{array}{l}\text { Reports to the FRMAC Manager and will } \\
\text { coordinate and direct FRMAC personnel } \\
\text { including those of the DOE, EPA, state } \\
\text { and participating federal agencies. } \\
\text { Involved in aerial surveys and } \\
\text { radiological monitoring, field monitoring, } \\
\text { sampling, radioanalysis (mobile and fixed } \\
\text { laboratory) and data control. Evaluate the } \\
\text { need for field monitoring, environmental } \\
\text { sampling and radioanalytical data. }\end{array}$ & $\begin{array}{l}\text { Detailed knowledge, expertise, and } \\
\text { proficiency with all phases of } \\
\text { radiological monitoring techniques, } \\
\text { health physics instrumentation and } \\
\text { environmental sampling } \\
\text { methodologies. Demonstrated ability } \\
\text { to manage an emergency response } \\
\text { field monitoring mission in stressful } \\
\text { urgent situations. }\end{array}$ \\
\hline $\begin{array}{l}\text { Deputy } \\
\text { Monitoring }\end{array}$ & $\begin{array}{l}\text { As an assistant/alternate to the } \\
\text { Monitoring Manager, coordinates and } \\
\text { directs all CM/FRMAC activities. } \\
\text { Involved in aerial radiological } \\
\text { monitoring, field monitoring, sampling } \\
\text { and radioanalysis (mobile and } \\
\text { Institutional laboratories). Identifies } \\
\text { equipment, personnel, and resource } \\
\text { requirements and coordinates their } \\
\text { availability. }\end{array}$ & $\begin{array}{l}\text { Knowledge and proficiency with } \\
\text { radiological monitoring techniques, } \\
\text { Health Physic instrumentation and } \\
\text { environmental sampling } \\
\text { methodologies. }\end{array}$ \\
\hline $\begin{array}{l}\text { Documentation } \\
\text { Specialist- } \\
\text { Support Unit }\end{array}$ & $\begin{array}{l}\text { Will document and track the status of all } \\
\text { CM/FRMAC requests, priorities and } \\
\text { activities for support including resources } \\
\text { and data products. Will ensure that all } \\
\text { documented activities, correspondence, } \\
\text { situation reports, action requests, lesson } \\
\text { learned, is archived in an accountable, } \\
\text { secure and retrievable form. }\end{array}$ & $\begin{array}{l}\text { Knowledge in the package and } \\
\text { preparation of the CM/FRMAC } \\
\text { equipment. Working knowledge and } \\
\text { experience in CM/FRMAC } \\
\text { missions, resources, capabilities, } \\
\text { objectives, and operations. }\end{array}$ \\
\hline
\end{tabular}




\begin{tabular}{|c|c|c|}
\hline POSITION & RESPONSIBILITIES & $\begin{array}{l}\text { KNOWLEDGE } \\
\text { AND SKILLS }\end{array}$ \\
\hline $\begin{array}{l}\text { Field Monitoring } \\
\text { Specialist }\end{array}$ & $\begin{array}{l}\text { Executes radiological field monitoring } \\
\text { and environmental sampling duties } \\
\text { according to established and documented } \\
\mathrm{CM} / \text { FRMAC methodologies in a safe, } \\
\text { consistent, efficient and timely manner. Is } \\
\text { responsible for performing Quality } \\
\text { Control response checks on } \\
\text { instrumentation. May provide training to } \\
\text { local responders in field monitoring } \\
\text { sampling, and/or contamination control } \\
\text { procedures. }\end{array}$ & $\begin{array}{l}\text { Knowledge and expertise with broad } \\
\text { spectrum of radiological } \\
\text { instrumentation including alpha/beta } \\
\text { contamination, gamma exposure } \\
\text { rate, and gamma Spectroscopy. } \\
\text { Experience in radiological } \\
\text { contamination control and } \\
\text { decontamination procedures. }\end{array}$ \\
\hline $\begin{array}{l}\text { Field Team } \\
\text { Supervisor }\end{array}$ & $\begin{array}{l}\text { Works under the CM/FRMAC } \\
\text { Monitoring Manager to coordinate and } \\
\text { direct all Field Monitoring Teams, Net } \\
\text { Control and Status Map activities. } \\
\text { Organizes the field teams, assigns tasks } \\
\text { and evaluates field monitoring resources } \\
\text { and requests for field monitoring requests } \\
\text { and priorities. Responsible for } \\
\text { maintaining all calibration, maintenance } \\
\text { and Quality Control documentation. }\end{array}$ & $\begin{array}{l}\text { Knowledge, expertise and } \\
\text { proficiency with all phases of } \\
\text { radiological monitoring, } \\
\text { environmental sampling and } \\
\text { radioanalytical methodologies. } \\
\text { Knowledge of sample } \\
\text { control/hotline sample receipt } \\
\text { methods and procedures. }\end{array}$ \\
\hline $\begin{array}{l}\text { AMS Mission } \\
\text { Scientist }\end{array}$ & $\begin{array}{l}\text { Works under the CM/FRMAC } \\
\text { Monitoring Manager. Coordinates and } \\
\text { directs the fixed-wing and helicopter } \\
\text { aerial survey missions. Ensures the initial } \\
\text { data analysis quality and submittal. } \\
\text { Assists in producing the aerial data } \\
\text { survey maps with GIS and Assessment } \\
\text { personnel. }\end{array}$ & $\begin{array}{l}\text { Knowledge, expertise and } \\
\text { proficiency with all phases of the } \\
\text { aerial survey missions. Ability to } \\
\text { evaluate potential hazards during } \\
\text { aerial missions to ensure the safety } \\
\text { of the flight crew and aircraft with } \\
\text { concurrence of the pilot-in- } \\
\text { command. }\end{array}$ \\
\hline $\begin{array}{l}\text { In situ Gamma } \\
\text { Spectroscopy } \\
\text { Scientist }\end{array}$ & $\begin{array}{l}\text { Responsible for the overall in situ gamma } \\
\text { spectroscopy support that FRMAC } \\
\text { provides. }\end{array}$ & $\begin{array}{l}\text { Knowledge, expertise and } \\
\text { proficiency with all phases of field } \\
\text { measurements with in situ systems } \\
\text { and software. Assists in } \\
\text { identification of radionuclides using } \\
\text { system software. }\end{array}$ \\
\hline $\begin{array}{l}\text { Net Control Radio } \\
\text { Dispatcher- } \\
\text { Support } \\
\text { Unit }\end{array}$ & $\begin{array}{l}\text { Responsible for recording and } \\
\text { documenting all monitoring and sampling } \\
\text { data and information transmitted by the } \\
\text { field monitoring teams via the two way } \\
\text { radios system or telephones. }\end{array}$ & $\begin{array}{l}\text { Knowledge of field monitoring } \\
\text { procedure, techniques tasks, } \\
\text { instrumentation, data produced and } \\
\text { the units associated with the data. }\end{array}$ \\
\hline
\end{tabular}




\section{APPENDIX E}

\section{MONITORING, HEALTH AND SAFETy INSTRUMENTS*}

\begin{tabular}{|c|c|c|c|c|}
\hline $\begin{array}{l}\text { Model } \\
\text { Name }\end{array}$ & Description & $\begin{array}{c}\text { Phase } \\
1\end{array}$ & $\begin{array}{c}\text { Phase } \\
2\end{array}$ & Total \\
\hline $\begin{array}{l}\text { NRC KIT: } \\
\text { ADM-300 }\end{array}$ & Exposure Rate Meter - Part of NRC Kit & 6 & 14 & 20 \\
\hline $\begin{array}{l}\text { NRC Kit: } \\
\text { BGP-100 }\end{array}$ & Exposure Rate Meter - Part of NRC Kit & \multirow{3}{*}{\multicolumn{3}{|c|}{$\begin{array}{l}\text { The BGP- } 100 \text {, BP- } 100 \text {, and } \\
\text { the AP- } 100 \text { are Smart Probes } \\
\text { that are part of the NRC Kit. }\end{array}$}} \\
\hline $\begin{array}{l}\text { NRC Kit: } \\
\text { BP-100 }\end{array}$ & $\begin{array}{l}\text { Beta/Gamma Contamination Probe - Part of } \\
\text { NRC Kit }\end{array}$ & & & \\
\hline $\begin{array}{l}\text { NRC Kit: } \\
\text { AP-100 }\end{array}$ & Alpha Contamination Probe - Part of NRC Kit & & & \\
\hline Garmin & GPS Unit & 6 & 14 & 20 \\
\hline TSA & Violinist III & 6 & 14 & 20 \\
\hline Canberra & HPGe In situ Systems & 1 & 5 & 6 \\
\hline PD-10i & Electronic Pocket Dosimeter & 30 & 40 & 70 \\
\hline TLDs & TLDs & 35 & 475 & 510 \\
\hline $\mathrm{BZA}$ & Breathing Zone Air Sample Pump & 6 & 16 & 22 \\
\hline \multirow[t]{6}{*}{ Staplex } & High Volume Air Sample Pumps & 2 & 8 & 10 \\
\hline & Hi-Vol A/S Pumps 4 inch Sample Holder & 2 & 8 & 10 \\
\hline & Hi-Vol AVS Pumps $8 \times 10$ inch Sample Holder & N/A & 8 & 8 \\
\hline & Low Volume Air Sample Pumps & $\mathrm{N} / \mathrm{A}$ & 9 & 9 \\
\hline & Lo-Vol A/S 2 in Sample Paper (boxes) & $\mathrm{N} / \mathrm{A}$ & 11 & 11 \\
\hline & Lo-Vol A/S Silver Zeolite Cartridges & $\mathrm{N} / \mathrm{A}$ & 80 & 80 \\
\hline Radeco & Grab Sample Air Sample Pumps & $\mathrm{N} / \mathrm{A}$ & 4 & 4 \\
\hline Ludlum 2929 & Alpha/Beta Swipe Counters & $\mathrm{N} / \mathrm{A}$ & 3 & 3 \\
\hline PPM-2000 & Personnel Portal Monitors & N/A & 2 & 2 \\
\hline \multirow[t]{2}{*}{ PID } & Photoionization Detector & $\mathrm{N} / \mathrm{A}$ & 2 & 2 \\
\hline & Sample Collection Kits & 1 & 20 & 21 \\
\hline Drager & Gas Detector Hazmat Kit & $\mathrm{N} / \mathrm{A}$ & 1 & 1 \\
\hline Quest & Heat Stress Monitor & $\mathrm{N} / \mathrm{A}$ & 2 & 2 \\
\hline \multirow[t]{2}{*}{ Quest } & Sound Level Meter & $\mathrm{N} / \mathrm{A}$ & 2 & 2 \\
\hline & Portable Shower & $\mathrm{N} / \mathrm{A}$ & 1 & 1 \\
\hline \multirow[t]{2}{*}{ Generators } & Generators, Internal Combustion Engines & $\mathrm{N} / \mathrm{A}$ & 22 & 22 \\
\hline & Fire Extinguishers & N/A & 22 & \multirow[t]{2}{*}{22} \\
\hline & $\begin{array}{l}\text { This list represents the instruments used as of the date } \mathrm{o} \\
\text { change as new equipment and technologies become ava }\end{array}$ & $\begin{array}{l}\text { his manual. } \\
\text { ble. }\end{array}$ & e list will & \\
\hline
\end{tabular}




\section{Personnel Protective Equipment (PPE)}

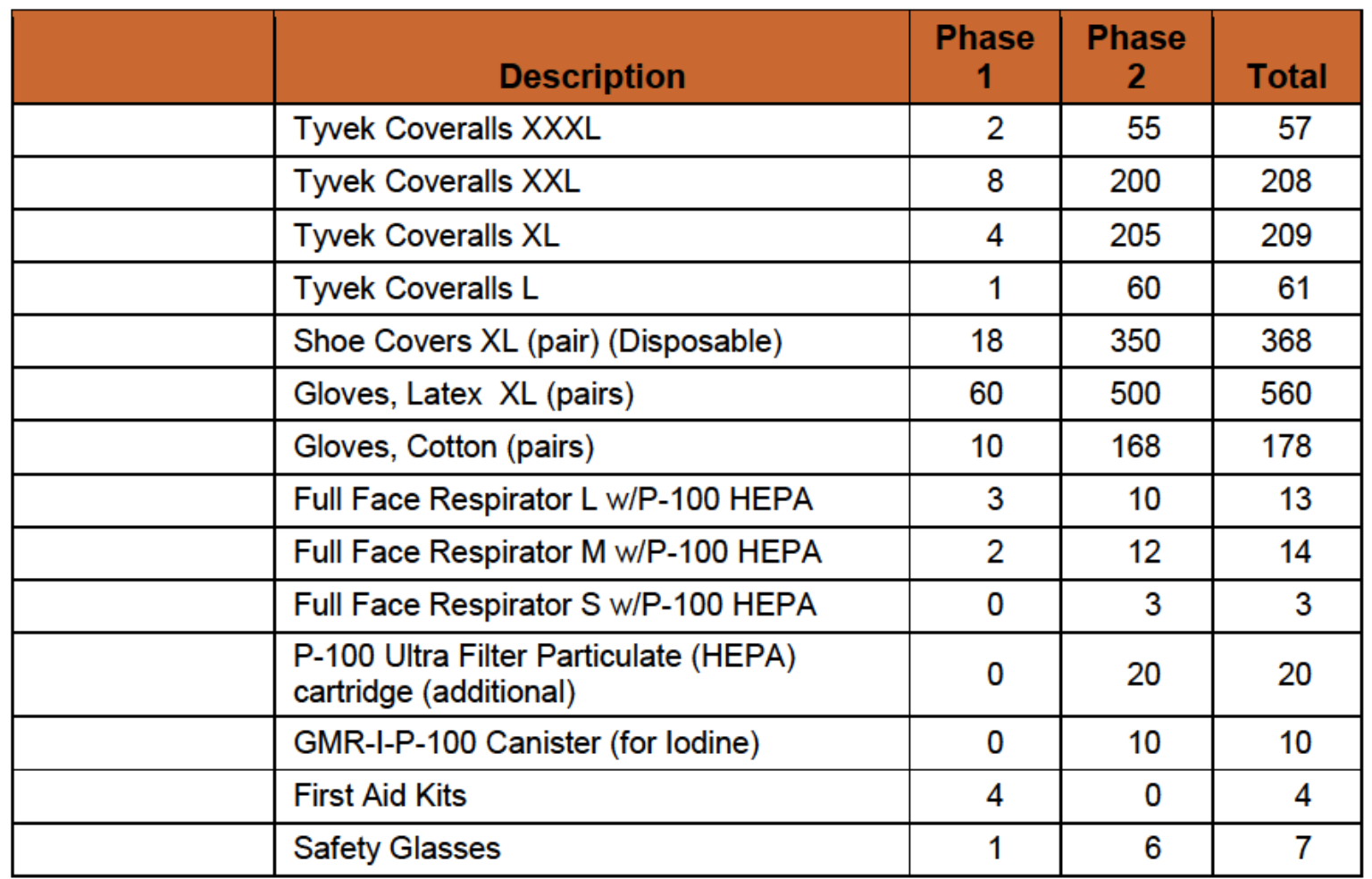

\section{Comsec}

\begin{tabular}{|l|l|c|c|c|}
\hline \multicolumn{1}{|c|}{ Description } & Phase & Phase & \\
& \multicolumn{1}{|c|}{} & \multicolumn{1}{|c|}{$\mathbf{2}$} & Total \\
\hline & Laptops (with Classified Hard Drives) & 2 & 0 & 2 \\
\hline & Cellular STUs & 2 & or 2 & 2 \\
\hline & Secure Fax & 1 & or 2 & 1 \\
\hline & & & & \\
\hline
\end{tabular}

Rev. 10/11 


\section{APPENDIX F \\ Monitoring Manager Checklist}

The following checklist should be considered as the minimum requirements for this position. Note that some of the tasks are one-time actions; others are ongoing or repetitive for the duration of the incident.

\section{Task}

1. Obtain briefing from FRMAC Manager:

- Determine incident objectives and recommended strategies.

- Determine status of current assignments.

- Identify current organization, location of resources, and assignments.

- Confirm resource ordering process.

- Determine location of current Staging Areas and resources assigned there.

2. Organize Monitoring Unit to ensure operational efficiency, personnel safety and adequate span of control.

3. Establish or confirm operational period.

4. Establish and demobilize Staging Areas for field teams.

5. Attend Deployment Briefing and assign monitoring personnel in accordance with Incident Action Plan (IAP):

- Brief Field Team Supervisors on types and numbers of field teams to be created and maintained.

- Brief tactical elements (Field Team Leaders) on assignments, dosimetry, PPE, data requirements and communications.

6. Develop and manage monitoring operations to meet incident objectives.

7. Assess life safety:

- Adjust field team routes, as necessary, to ensure scene security.

- Evaluate and enforce use of appropriate protective clothing and equipment.

- Implement and enforce appropriate safety precautions.

8. Evaluate situation and provide updates to FRMAC Manager:

- Location, status, and assignment of resources.

- Effectiveness of data flow and sampling.

- Desired contingency plans.

Rev. 10/11 
9. Determine need and request additional resources.

10. Notify Support Manager of unit staff, including location of resources and names of leaders.

11. Keep Support Manager to date on changes in resource status.

12. Write formal Operations portion of IAP with the Assessment Scientist(s) and H\&S officer, if so directed by the FRMAC Manager:

- Identify assignments by field team.

- Identify specific tactical assignments (instrument readings, air sampling, sample collection).

- Identify resources needed to accomplish assignments.

13. Ensure coordination of the Monitoring unit with other FRMAC units:

- Ensure Monitoring Unit activity logs, and equipment use documents are maintained and passed to Document Control, as appropriate.

- Ensure resource ordering and logistical support needs are passed to the Support Manager in a timely ordering process.

- Notify communication group of problems.

- Notify Support Manager of issues concerning cooperating and assisting agency resources.

- Keep Health and Safety Officer involved in tactical decision-making.

- Keep FRMAC Manager apprised of status of operational efforts.

14. Attend a Tactics/DQO Meeting with the Assessment Scientist, H\&S Officer, and FRMAC Manager prior to the IAP completion and submittal to the FRMAC Director to review strategy, discuss tactics, and outline organization assignments.

15. Attend UC Planning Meetings, if necessary.

\begin{tabular}{ll}
\hline \multicolumn{1}{c}{ Sample FRMAC Planning Meeting Agenda } \\
\hline \multicolumn{1}{c}{ Agenda Item } & \multicolumn{1}{c}{ Responsible Party } \\
1. Briefing on situation/resource status. & Monitoring/Support/Assessment \\
2. Discuss safety issues. & Safety Officer \\
3. Set/confirm incident objectives. & FRMAC Manager \\
4. Develop field teams. & Monitoring \\
5. Specify tactics for each field team/AMS aircraft. & Monitoring/Assessment/Laboratory \\
6. Specify resources needed for each field team. & Monitoring/Support \\
7. Specify facilities and reporting locations. & Monitoring/Support \\
8. Create field team routes/AMS surveys. & Monitoring/Assessment/H\&S \\
9. Consider communications/medical/ transportation & Monitoring/Support/H\&S \\
plans/air space clearance. & \\
10. Discuss information issues. & FRMAC Manager/PIO \\
11. Finalize/approve/implement plan. & FRMAC Manager/All \\
\hline \hline
\end{tabular}

16. Hold Unit meetings, as necessary, to ensure communication and coordination among Operations Branches, Divisions, and Groups.

Rev. 10/11

F-2 


\section{APPENDIX G \\ MONITORING \& SAMPLING UNIT DQO CHECKLIST}

The following checklist should be considered as the minimum requirements for this process. Note that some of the tasks are one-time actions; others are ongoing or repetitive for the duration of the incident. Tasks may be delegated to the appropriate Unit Leader.

\section{Task}

1. Obtain briefing from FRMAC Manager:

- Determine current incident status.

- Determine current incident objectives and strategy.

- Determine time and location of first DQO Meeting.

- Determine desired contingency plans.

2. Establish and maintain data tracking system.

3. Compile and display incident data status summary information.

4. Obtain/develop data product maps.

5. Prepare field team DQO's:

- Review current and projected field team and AMS status.

- Identify resources required to implement DQO's in plan.

- Document DQO alternatives for presentation to FRMAC Manager, and for inclusion in the written IAP.

a. Mobile field team parameters include: survey instrument reporting units (alpha, beta, and gamma), survey routes and spacing, turn-back levels.

b. Air sampling parameters include: sampler location(s), flow rates, run times, filter types.

c. Sample collection parameters include: sample locations, sample type, volume, packaging, screening levels.

d. AMS survey parameters include: survey area, altitude, line spacing, reporting units, nuclides of interest.

e. In situ survey parameters include: location, count times, instrument dead times, regions of interest (ROls).

6. Meet with Assessment, H\&S, and Support units, prior to DQO Meetings, to discuss proposed strategy and tactics.

Rev. 10/11 
7. Conduct DQO Meetings according to following agenda:

\section{Sample DQO Meeting Agenda}

\section{Agenda Item}

1. Briefing on situation/resource status.

2. Discuss safety issues.

3. Set/confirm incident objectives.

4. Plot incident control lines $\&$ boundaries.

5. Specify monitoring and sampling tactics for each field team/aircraft.

6. Specify resources needed for each field team.

7. Specify facilities and reporting locations.

8. Consider communications/medical/ transportation plans.

9. Discuss interagency monitoring and sampling issues.

10. Discuss information issues.

11. Finalize/approve/implement DQO's into IAP.

\section{Responsible Party}

Unit Managers

Health \& Safety Officer

FRMAC Manager

Monitoring/H\&S

Monitoring/Assessment/H\&S

Monitoring/H\&S/Support Units

Monitoring/H\&S/Support

Monitoring/H\&S/Support

Monitoring/Assessment/Local Agencies

Public Information Officer

Monitoring Manager/All

8. Supervise preparation and distribution of the written DQO's, if indicated. Minimum distribution is to all FRMAC Monitoring and Sampling personnel and to the other unit managers:

- Establish information requirements and reporting schedules for use in preparing the DQO's.

- Ensure that detailed contingency plan information is available for consideration by the FRMAC Manager.

- Verify that all support and resource needs are coordinated with Support Unit prior to approval of the DQO's.

9. Coordinate development of Incident Traffic Plan with H\&S and Support Unit Leaders.

10. Coordinate preparation of the Safety Message with Health \& Safety Officer.

11. Establish a weather data collection system, when necessary.

12. Identify need for specialized resources; discuss need with Support Manager.

13. Provide briefing to relief on current and unusual situations.

14. Submit all Section documentation to Documentation Unit. 


\section{APPENDIX H \\ AMS Mission Scientist CHECKLIST}

The following checklist should be considered as the minimum requirements for this position. Note that some of the tasks are one-time actions; others are ongoing or repetitive for the duration of the incident.
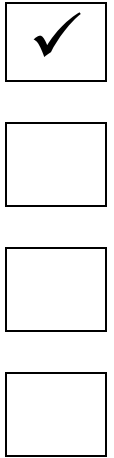

3. Brief subordinate staff:

- Incident and work objectives, schedules, mission requirements, priorities, time schedules, and process for briefings and debriefings.

- Work-site locations, status of aircraft, and crews and equipment assigned or ordered.

4. Assign personnel to utilize skills and qualifications, and make adjustments, as needed.

5. Establish line of authority and procedures for decision making.

6. Debrief personnel and pilots and make assignment and staffing adjustments, as necessary:

- Identify safety issues and hazards, and mitigate them.

- Determine aircraft status.

- Identify pilot and aircraft mission capabilities.

- Initiate system to monitor flight/duty hour limitations and ensure they are not exceeded.

7. Collect and process incident reports, NARAC plots, points-of-contact:

- Develop operations plan

- Complete deployment hazard analysis

- Adjustment to Incident Action Plan (IAP) and support needs for other sections.

8. Inspect and visit areas of operation to insure compliance with agency rules, regulations, and procedures.

Rev. 10/11 
9. Provide for the safety and welfare of assigned personnel during the entire period of supervision:

- Recognize potentially hazardous situations (radiological and non-radiological).

- Inform subordinates of hazards and turn-back levels.

- Control positions and function of resources.

- Ensure that special precautions are taken when extraordinary hazards exist.

- Maintain work/rest guidelines.

10. Review data products and priorities for planning meeting (development of IAP):

- Confirm status and availability of aircraft and personnel for the next and future operational periods.

11. Participate in the planning and strategy meeting:

- Advise Monitoring Manager of capabilities and/or limitations to support the IAP.

- Determine mission priority.

- Identify start/stop times for UC Aviation Operations Branch notification.

- Make assignments to carry out IAP.

- Identify mission parameters that meet the objectives of the IAP.

12. Determine what information Aviation Operations Branch needs to clear air space.

13. Coordinate with FRMAC Monitoring Unit/UC Air Operations Branch:

- Ensure that a Temporary Flight Restriction has been initiated, if appropriate, and is in effect over the incident.

- Ensure that contact has been established with the military for special use airspace.

- Provide current information on status of aircraft (type, tail number, FBO).

- Establish procedures for emergency reassignment of aircraft on the incident.

14. Prepare demobilization schedule of aircraft, personnel, and equipment and coordinate with Monitoring Manager and Support Manager.

15. Document all activity.

Rev. 10/11 


\section{APPENDIX I \\ AMS HOME TEAM SCIENTIST CHECKLIST}

The following checklist should be considered as the minimum requirements for this position. Note that some of the tasks are one-time actions and others are ongoing or repetitive for the duration of the incident. Tasks may be delegated to the appropriate Unit Leader

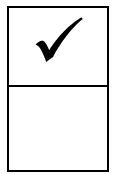

\section{Task}

1. Obtain briefing from AMS Mission Scientist/RSL Response Manager:

- Determine current aircraft/air crew status

- Determine current situation status/intelligence.

- Determine current incident objectives and strategy.

- Determine whether mission scientist requires a written Operations Plan.

- Determine time and location of first ER home team Planning Meeting.

- Determine desired contingency plans.

2. Activate AMS Section positions, as necessary, and notify AMS manager of positions activated.

3. Establish and maintain resource tracking system.

4. Advise ER home team staff of any significant changes in incident status.

5. Compile and display incident status summary information.

- Forward incident status summaries to AMS mission scientist.

- Obtain latest NARAC prediction, if applicable.

6. Obtain/develop incident maps.

7. Provide AMS technicians with GIS shapefiles for the aircraft acquisition systems.

8. Prepare contingency plans:

- Review current and projected incident and resource status.

- Develop alternative strategies.

- Identify resources required to implement contingency plan.

- Document alternatives for presentation to mission scientist/RSL Response Manager, and for inclusion in the written operations plan. 
9. Attend Planning Meetings according to following agenda:

\section{Sample Planning Meeting Agenda}

\section{Agenda Item}

1. Briefing on situation/resource status.

2. Discuss safety issues.

3. Set/confirm incident objectives.

4. Plot AMS survey boundaries.

5. Confirm mission parameters for each aircraft.

6. Specify resources needed for data analysis.

7. Discuss data analysis and products.

8. Finalize/approve/implement operations plan.

\section{Responsible Party}

ER Home Team

RSL Safety Officer

Response Manager/Monitoring Mgr

Response Manager/Monitoring Mgr

Mission Scientist/Monitoring Mgr

Mission Scientist/Monitoring Mgr

Monitoring/Assessment

Monitoring Mgr/Mission Scientist

10. Prepare contingency plans:

- Establish data product requirements and reporting schedules.

- Ensure that detailed contingency plan information is available for consideration by Mission Scientist and Monitoring Manager.

- Verify that all ER Home Team support and resource needs are coordinated with Home Team Response Manager.

11. Coordinate development of an Air Space Clearance Plan with Mission Scientist and Pilot-InCommand.

12. Coordinate preparation of the initial deployment hazard analysis with RSL Safety Officer.

13. Coordinate preparation of an AMS Communications Plan, if necessary.

14. Establish a weather data collection system, when necessary.

15. Ensure AMS home team scientist position has adequate coverage and relief.

16. Attend ER Home Team meetings as necessary to ensure communication and coordination among Home Team Units.

17. Ensure preparation of AMS demobilization plan, if appropriate.

18. Ensure preparation of final AMS data packages and route to FRMAC and CM Web, if directed.

19. Provide briefing to relief scientist on current and unusual situations and data product status.

Rev. 10/11 


\section{APPENDIX J \\ FIELD TEAM SUPERVISOR CHECKLIST}

The following checklist should be considered as the minimum requirements for this position. Note that some of the tasks are one-time actions; others are ongoing or repetitive for the duration of the incident.
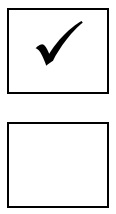

1. Obtain briefing from Monitoring Manager or Deputy.

- Review ICS Form 201 for incident status.

- Determine/confirm resources assigned to field monitoring teams.

- Confirm monitoring and sampling assignment objectives.

- Determine necessary contingency plans.

- Deliver rosters to monitoring manager or deputy, if indicated.

- Confirm internal and external communications.

2. Organize and staff field teams, as appropriate:

- Assign field team specialists.

- Request other Technical Specialists or local escorts, as needed.

3. Supervise field teams as assigned (on very complex incidents, it may be necessary to assign a field team supervisor to oversee specific field teams):

- Brief Field Team Specialists on current incident status.

- Assign analysis tasks.

- Notify staff of time lines and format requirements.

- Monitor progress.

- Coordinate activities with other FRMAC field team supervisors, if applicable.

4. Compile, maintain and display incident status information for Monitoring Manager staff:

- Sort data into required categories of information (i.e., geographic area, population, facilities, environmental values at risk, location of facilities, etc.).

- Determine appropriate map displays.

- Review all data for completeness, accuracy, and relevancy prior to posting.

- Plot incident boundaries, location of perimeters, facilities, access routes, etc. on display maps in monitoring unit planning area.

- Develop additional displays (weather reports, incident status summaries, etc.), as necessary.

- Ensure displays and maps are kept up to date. 
5. Provide photographic services and maps:

- Photographic services may be used to document operations and intelligence activities, public information activities, and accident investigations.

- Issue disposable or digital cameras to field team personnel as appropriate.

- Ensure photographs are processed at the end of each operational period.

- Request or develop additional and specialized maps as required.

- Provide Incident Map(s) for Incident Action Plan (IAP).

6. Provide situation evaluation, prediction and analysis for monitoring manager; prepare information on alternative strategies:

- Review current and projected incident and resource status.

- Develop alternative strategies.

- Identify resources required to implement contingency plan.

- Document alternatives for presentation to monitoring manager and inclusion in the written IAP, using the ICS Form 204, Contingency Plan.

7. Interview field team personnel coming off duty to determine effectiveness of strategy and tactics, work accomplished and left to be accomplished.

8. Request weather forecasts and spot weather forecasts, as necessary, directly from the National Weather Service.

9. Prepare Incident Status Summary (ICS Form 209) and other status reports, as assigned prior to each Planning Meeting:

- Provide copies to monitoring Staff.

- Forward to documentation control, as directed.

10. Participate in Planning Meetings, as required.

11. Prepare predictions at periodic intervals, or upon request of the Monitoring Manager. Notify monitoring staff if unforeseen changes occur.

12. Provide briefing to relief on current and unusual situations.

13. Document all activity on Unit Log (ICS Form 214).

Rev. 10/11 


\section{APPENDIX K \\ Field Monitoring Specialist Checklist}

The following checklist should be considered as the minimum requirements for this position. Note that some of the tasks are one-time actions; others are ongoing or repetitive for the duration of the incident.

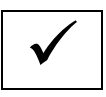

\section{Task}

1. Obtain briefing from Field Team Supervisor/Monitoring Manager and H\&S officer:

- Identify Supervisor in organization.

- Identify work location and maps, sampling routes and intervals, resources available, expectations concerning time-lines.

- Confirm data units for instruments, air sampler run times

- Procure supplemental dosimetry and PPE, if required.

- Attend Pre-deployment and safety briefings. Confirm turn-back levels and any nonradiological hazards.

- Confirm locations of FRMAC vehicle, personnel and sample control hotlines.

- Confirm locations of traffic barricades and exclusion zone entry and exit points, if applicable.

- Identify radioactive waste control procedures for used PPE and sample collection materials.

- Confirm communication protocols for data transmission and for team status reports to FRMAC.

2. Obtain copies of Incident Action Plan (IAP), if available, and Unit Log (ICS Form 214).

3. Participate in Planning Meetings, as requested.

4. Provide technical expertise to field team supervisor in organization according to established format, timelines, etc.

5. Document all activity on Unit Log (ICS Form 214).

Rev. 10/11 
This page intentionally blank 


\section{APPENDIX L \\ HEALTH \& SAFETy OfFICER CHECKLIST}

The following checklist should be considered as the minimum requirements for this position. Note that some of the tasks are one-time actions; others are ongoing or repetitive for the duration of the incident.

\section{Task}

1. Obtain briefing from FRMAC manager and/or from UC Safety Officer.

2. Identify hazardous situations associated with the incident. Ensure adequate levels of protective equipment are available, and being used.

3. Staff and organize function, as appropriate:

- In multi-discipline incidents, consider the use of an Assistant Safety Officer from each discipline.

- Multiple high-risk operations may require an Assistant Safety Officer at each site.

- Request additional staff through FRMAC Manager.

4. Identify potentially unsafe acts.

5. Identify corrective actions and ensure implementation. Coordinate corrective action with FRMAC unit leaders.

6. Debrief Assistant Safety Officers prior to Planning Meetings.

7. Prepare Incident Action Plan Safety and Risk Analysis (USDA ICS Form 215A).

8. Participate in Planning and Tactics Meetings:

- Listen to tactical options being considered. If potentially unsafe, assist in identifying options, protective actions, or alternate tactics.

- Discuss accidents/injuries to date. Make recommendations on preventative or corrective actions. 
9. Attend Planning meetings:

\section{Sample FRMAC Monitoring Planning Meeting Agenda}

\section{Agenda Item}

1. Briefing on situation/resource status.

2. Discuss safety issues.

3. Set/confirm monitoring objectives.

4. Plot sample routes and locations.

5. Specify tactics for each field team.

6. Specify resources needed for each monitoring team/asset.

7. Specify facilities and reporting locations.

8. Identify personnel, vehicle, sample hotlines

9. Consider communications/medical/ transportation plans.

10. Turn-back levels.

11. Discuss interagency liaison issues.

12. Discuss information issues.

13. Finalize/approve/implement plan.

\section{Responsible Party}

FRMAC Manager/ Unit Chiefs

H\&S Officer

FRMAC Manager/Monitoring Manager

Monitoring Manager

Monitoring Manager

Monitoring Mgr/Field Team Supv.

Monitoring Mgr/Field Team Supv.

H\&S Officer

Logistics/Planning Section Chiefs

H\&S Officer

FRMAC Liaison Officer

Public Information Officer

FRMAC Manager/All Unit Officers

10. Participate in the development of Incident Action Plan (IAP):

- Review and approve Medical Plan (ICS Form 206).

- Provide Safety Message (ICS Form 202) and/or approved document.

- Assist in the development of the "Special Instructions" block of ICS Form 204, as requested by the Planning Section.

11. Investigate accidents that have occurred within incident areas:

- Ensure accident scene is preserved for investigation.

- Ensure accident is properly documented.

- Coordinate with UC Safety Officer and responder's agency.

- Prepare accident report as per agency policy, procedures, and direction.

- Recommend corrective actions to FRMAC Manager.

12. Coordinate critical incident stress, hazardous materials, and other debriefings, as necessary.

13. Document all activity on Unit Log (ICS Form 214).

Rev. 10/11 


\section{APPENDIX M Support Unit MANAGER CHECKLIST}

The following checklist should be considered as the minimum requirements for this position. Note that some of the tasks are one-time actions; others are ongoing or repetitive for the duration of the incident.

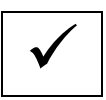

\section{Task}

1. Obtain briefing from FRMAC Manager:

- Determine facilities activated in support of the incident.

- Determine ground support and transportation needs.

- Determine resource ordering process.

- Confirm personnel already requested for FRMAC.

2. Confirm resource ordering process and who is authorized to order with FRMAC Manager and UC Logistics Section Chief, if required.

3. Confirm facilities in use and determine the potential for additional facilities.

4. Determine need for fuel delivery and vehicle support.

5. Determine whether or not mutual aid and contract equipment are in use. Confirm method of inspection.

6. Staff Unit appropriately.

7. Assemble, brief, and assign work locations and preliminary work tasks to Unit personnel:

- Provide summary of emergency situation.

- Provide summary of the facility, supply, and ground support needs of the incident.

8. Participate in organizational meetings of Support Unit personnel.

9. Coordinate activities of Support Unit function.

10. Keep FRMAC Manager apprised of Unit Activities.

11. Document all activity on Unit Log (ICS Form 214).

Rev. 10/11 
This page intentionally left blank

M-2 


\section{APPENDIX N \\ SUPPORT MANAGER COMMUNiCATION LEADER CHECKLIST}

The following checklist should be considered as the minimum requirements for this position. Note that some of the tasks are one-time actions; others are ongoing or repetitive for the duration of the incident.

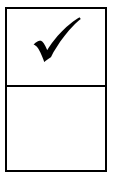

\section{Task}

1. Obtain briefing from the Support Manager/Monitoring Mgr/Field Team Supv.

2. Organize and staff FRMAC communication area as appropriate:

- Assign Communications Lead Incident Dispatcher/Radio Monitor.

3. Assess communications systems/frequencies in use; advise on communications capabilities/limitations.

4. Develop and implement effective communications procedures (flow) internal and external to the FRMAC.

5. Assess FRMAC phone load and request additional lines as needed.

6. Prepare and implement FRMAC Communications Plan:

- Obtain current organizational chart.

- Determine most hazardous tactical activity; ensure adequate communications.

- Make communications assignments to all other field team elements.

- Determine communications protocols.

- Determine support communications needs.

- Establish and post any specific procedures for use of FRMAC communications equipment.

7. Include cellular phones and pagers in Incident Communications Plan (ICS Form 205), if appropriate:

- Determine specific organizational elements to be assigned telephones.

- Identify all facilities/locations with which communications must be established (shelters, press area, liaison area, agency facilities, other governmental entities' Emergency Operations Centers (EOCs), etc.), identify and document phone numbers.

- Determine which phones/numbers should be used by what personnel and for what purpose. Assign specific telephone numbers for incoming calls, and report these numbers to staff and off-site parties such as other local jurisdictions, state and federal agencies.

- Do not publicize OUTGOING call lines. 
8. Activate, serve as contact point, and supervise the integration of volunteer radio organizations into the communications system.

9. Ensure radio and telephone logs are available and being used.

10. Determine need and research availability of additional nets and systems:

- Order through Supply Unit after approval by Section Chief.

- Federal systems:

- Additional radios and other communications devices, including repeaters, radiotelephone interconnects and satellite down-link capabilities may be available through other agencies.

11. Document malfunctioning communications equipment, facilitate repair.

12. Establish and maintain communications equipment accountability system.

13. Provide technical information, as required, on:

- Adequacy of communications system currently in use.

- Geographic limitation on communications equipment.

- Equipment capabilities.

- Amount and types of equipment available.

- Anticipated problems in the use of communications equipment.

14. Estimate Unit needs for expected operations; order relief personnel.

15. Provide briefing to relief on current activities and unusual situations.

16. Document all activity on Unit Log (ICS Form 214).

Rev. 10/11 


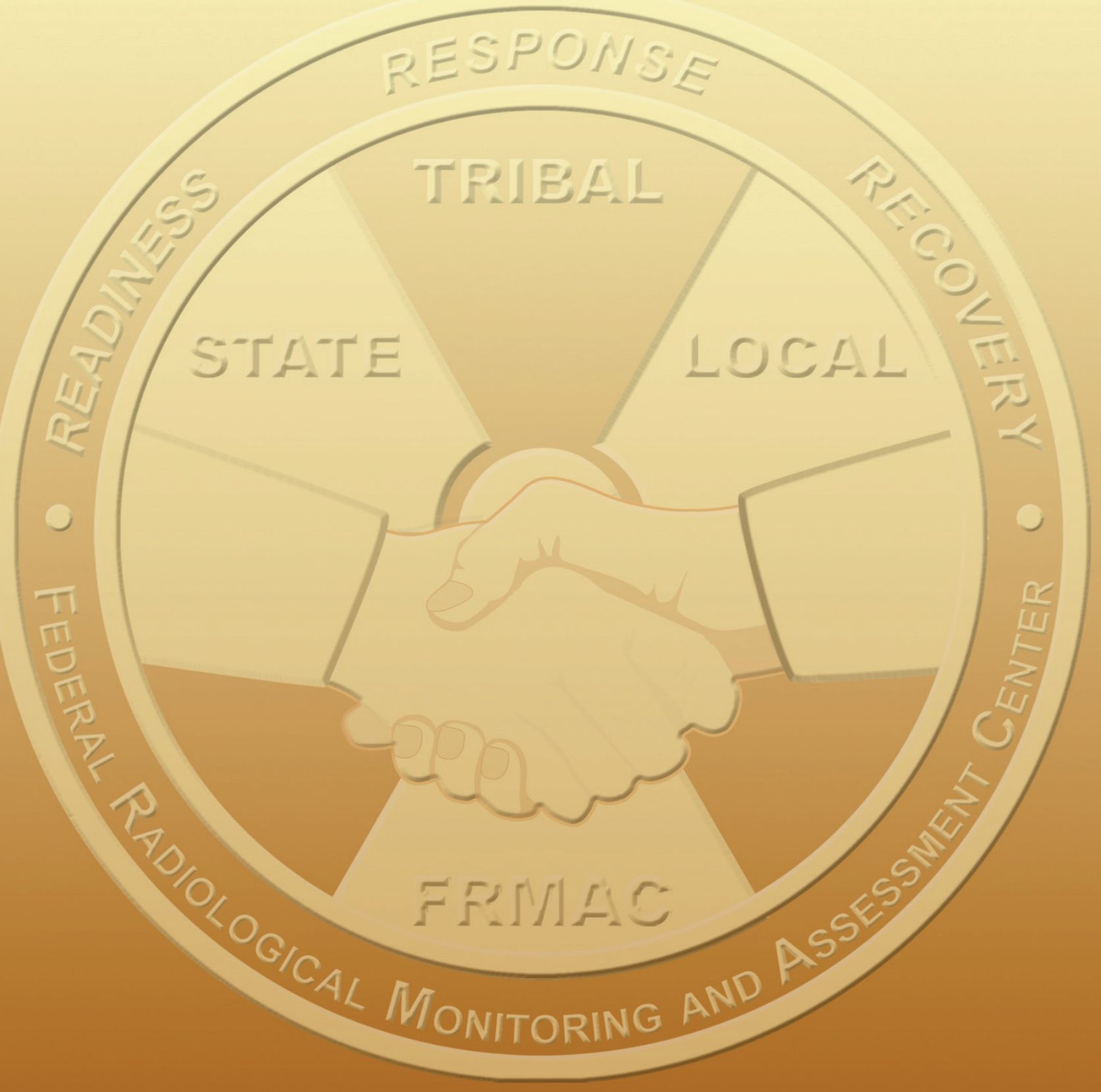

